\title{
Reinstitucionalización del testimonio en América Latina desde la narrativa humanitaria
}

\author{
Reinstitutionalization of testimony in Latin America under the human rights \\ narrative
}

Teresa Basile

terebasile@yahoo.com

Universidad Nacional de La Plata, Argentina

Recepción: 17 Octubre 2020

Aprobación: 08 Noviembre 2020

Publicación: 01 Diciembre 2020

Cita sugerida: Basile, T. (2020). Reinstitucionalización del testimonio en América Latina desde la narrativa humanitaria. Aletheia, 11(21), e067. https://doi.org/10.24215/18533701e067

\begin{abstract}
Resumen: Proponemos explorar la tradición del testimonio latinoamericano marcando dos modelos. En primer lugar, revisamos el testimonio de matriz revolucionaria, institucionalizado en 1970 por Casa de las Américas bajo el paradigma revolucionario y en cuyo interior analizamos tres tipos diferentes -el testimonio etnográfico, guerrillero y periodístico-. En segundo lugar abordamos la reinstitucionalización del testimonio bajo la narrativa de los Derechos Humanos hacia la década del 1980, focalizando en el caso Argentino. Nos interesa indagar los estatutos de cada modelo así como sus vínculos con el campo literario.
\end{abstract}

Palabras clave: Testimonio, Testimonio latinoamericano, Testimonio y derechos humanos, Memoria.

Abstract: We propose to explore the tradition of Latin American testimony by marking two models. First, we review the testimony of a revolutionary matrix, institutionalized in 1970 by Casa de las Américas under the revolutionary paradigm and within which we analyze three different types -the ethnographic, guerrilla and journalistic testimony. Second, we address the reinstitutionalization of testimony under the human rights narrative towards the 1980s, focusing on the Argentine case. We are interested in investigating the statutes of each model as well as its links with the literary field.

Keywords: Testimony, Latin American testimony, Testimony and human rights, Memory.

\section{Preliminares: de la Revolución a los Derechos Humanos ${ }^{1}$}

Uno de los géneros centrales en la historia cultural latinoamericana ha sido y sigue siendo el testimonio, en tanto ha permitido visualizar las historias de opresión de comunidades no tan visibles, de sectores olvidados o descuidados por el Estado, de sujetos situados en el margen al que no llegan los beneficios del ciudadano de primera, de grupos arrasados por los terrorismos de Estado, de sobrevivientes que hablan por ellos mismos y por los "desaparecidos", de exiliados y migrantes, de mujeres bajo violencia de género o sometidas a la trata de personas, de víctimas de diverso tipo de violencia y nuevos modos de yugo. De allí que se lo considere como un vehículo para dar voz a los "sin voz", para que el "subalterno" pueda finalmente 
hablar (Spivak, 1998), para percibir a los "condenados de la tierra" -diría Franz Fanon (1961)-, para denunciar y declarar en los juicios contra genocidas, para iluminar las grietas de nuestro presente o del pasado y saldar las deudas pendientes con estos sectores avasallados en sus derechos, para canalizar un relato alternativo a la historia oficial. Aun cuando muchos consideran que su despliegue y canonización en torno a las olas revolucionarias de los 60 fue un proyecto de las élites letradas solidarias con estos sectores, el testimonio consolidó un proceso de canonización de lo periférico, como sostiene Elzbieta Sklodowska (1988, p. 131). Pero también, y como complemento de la denuncia de los sistemas de dominio, los testimonios han dado cuenta de las luchas libertarias, las épicas revolucionarias, los levantamientos y revueltas emprendidas para superar y reconvertir estos contextos de sometimiento ya que, como sostiene John Beverley forma parte de la literatura de resistencia (1989, p. 24). Como vemos, aquello que atañe al testimonio es el cuestionamiento del poder. Se lo postula y construye como un género "genuinamente latinoamericano" con una vasta tradición de linajes de discursos contestatarios desde la Conquista.

En esta ocasión proponemos explorar la reinstitucionalización del testimonio en América Latina hacia la década de 1980 bajo el paradigma de los derechos humanos que redefine la tradición anterior fuertemente anclada en el dispositivo revolucionario. Los procesos constituyentes (Agamben, 1999) en el campo cultural y en la institución literaria suelen tener lugar en contextos de profundos cambios que requieren diseñar nuevos modos de gestión cultural y social. En esta segunda ola es posible percibir, además, una diseminación del testimonio que invade diversos saberes, instituciones y prácticas políticas (la justicia, los museos, las militancias, etc.), una apertura desde el primer testimonio sobre la desaparición hacia testimonios de víctimas de otro tipo de violaciones de derechos humanos (femicidios, narcotráfico, migrantes, etc.), y una nueva articulación de este género con la literatura y diversas formas del arte.

Cabe aclarar que el testimonio no se reduce a una testificación o declaración suelta, sino que se construye como tal y por ello precisa de instituciones que autoricen a sus enunciadores, convaliden la "realidad" del acontecimiento narrado y certifiquen su "verdad". En nuestro caso esos dispositivos de validación remiten a la administración cultural de la Revolución cubana y a los letrados latinoamericanos que la apoyan en el primer caso y, en el segundo caso (referido a Argentina), a la instauración de instituciones y políticas de memoria, verdad y justicia durante la refundación de la democracia llevada a cabo por el gobierno de Raúl Alfonsín luego de la dictadura (1976-1983). Por otra parte, los testimonios no son irrefutables, llegan a constituirse como válidos luego de peleas y debates por los sentidos de los acontecimientos, configuran verdades en construcción a lo largo del tiempo en diversas reinscripciones, más allá de su deseo de fijar una verdad definitiva que se pretenda natural.

Varios trabajos críticos han procurado delimitar distintos tipos de testimonios. Veamos algunos de los criterios empleados para clasificarlos. John Beverley desde una pauta basada en la tensión entre lo literario y lo no literario, lo ficticio y lo fáctico, es decir los diferentes grados en que el testimonio se hibridiza con la ficción, distingue entre cuatro especies: el testimonio sensu stricto, la novela testimonial en la líneas de la non fiction, la novela pseudotestimonial, y formas ambiguas entre el testimonio y la novela testimonial (Beverley, 1989, p. 81). En cambio René Jara elige la índole del acontecimiento que articula el testimonio. Observa dos modelos: aquel que se origina en una atmósfera de represión, ansiedad y angustia, y focaliza en los sistemas de opresión y el que responde a momentos de exaltación heroica en los avatares de la organización guerrillera y en el peligro de la lucha armada, y celebra las épicas revolucionarias que vienen a terminar con siglos de sometimiento (Jara, 1986, p. 2).

En su texto Testimonio hispanoamericano: historia, teoría, poética (1992) Elzbieta Sklodowska distingue entre testimonios mediatizados -aquellos en que un editor transcribe un discurso oral de un interlocutor informante- y testimonios inmediatos o directos que carecen de la presencia de un editor como la entrevista, la autobiografía, diario, memoria, crónica, testimonio legal. Dentro del discurso testimonial mediatizado reconoce el testimonio noticiero, el testimonio etnográfico y sociobistórico, la novela testimonial y la pseudotestimonial. De este modo coloca como criterios la autoría conjunta o individual en primer término y luego la disciplina o discurso desde el cual proviene, pero también considera la preferencia entre el acto de testimoniar 
y la función poética que daría lugar a una mayor o menor novelización del testimonio (1992, p. 98-102). ${ }^{2}$ En La escritura testimonial en América Latina (2002), Rossana Nofal también advierte la diferencia que suponen los testimonios que no están escritos por un sujeto analfabeto o informante, y a partir de esta observación distingue entre el testimonio canónico y el testimonio letrado colocando como parámetro distintivo la categoría de autor. El testimonio letrado, basado en el relato sin mediaciones de una experiencia personal, se subdivide en dos categorías: aquellos que dan cuenta de una flagelación corporal y aquellos que se definen como memorias de una militancia.

Mabel Moraña en "Documentalismo y ficción: testimonio y narrativa testimonial hispanoamericana en el siglo XX" (1997) distingue dentro de lo que denomina "literatura testimonial o documentalista" cuatro grandes grupos: los testimonios de la lucharevolucionaria surgidos en torno a las revoluciones latinoamericanas y las luchas de liberación nacional de los 60, pero que tiene antecedentes como el Diario de campaña (1895) de José Marí, el testimonio de la resistencia popular en el Cono Sur gestado en torno a las dictaduras de la década de los 70 en Chile, Argentina y Uruguay, y el testimonio y biografía femenina que junto al testimonio desde los márgenes exhiben el cruce de múltiples factores de subalternidad como la clase social, la etnicidad, el género sexual, la ideología, etc.

Recientemente Jaume Peris Blanes y Gema Palazón Sáez han propuesto una necesaria actualización del debate sobre los nuevos modos del testimonio latinoamericano en el contexto de la globalización neoliberal y de las nuevas formas de violencia sistémica que azotan América Latina en un importante dossier "Avatares del testimonio en América Latina: tensiones, contradicciones, relecturas..." (2015). Se expone la diversidad de contextos en los que se enuncian así como se advierte sobre sus diferentes usos político-culturales (desde las luchas sociales hasta los proyectos conservadores o su captura por las industrias culturales). Los editores plantean claramente dos grandes grupos: el primero aborda el archivo de los testimonios ya consolidados que tuvieron un rol destacado en las luchas políticas o culturales del pasado (las formas clásicas del testimonio), y el segundo refiere a las prácticas testimoniales del presente en relación con las luchas políticas y sociales de la actualidad. Señalan además la percepción de cierta dificultad para pensar la continuidad entre uno y otro grupo, y ese es justamente el punto que nos interesa abordar (Peris Blanes y Palazón Sáez, 2015, p. 1-8).

En estos recorridos se emplean criterios literarios (tensión entre lo factual y lo ficcional), autoriales (editor, informante, autor), disciplinarios (etnografía, periodismo, sociología, historia, literatura) o acontecimentales (sistemas de opresión y luchas libertarias) que iluminan la complejidad de los testimonios. En nuestro caso vamos a apuntar a la matriz que los legitima -la revolución y los derechos humanos- en tanto nos permiten marcar un cambio de paradigma desde las décadas de los 60 a los 80 . Esta distinción no ignora que todo intento conceptualizador, clasificador, generalizador exhibe sus grietas y desajustes. Es posible detectar testimonios transicionales donde se exhibe el pasaje de uno a otro modelo, testimonios híbridos que crucen ambas matrices o ciertos textos que vuelven a inscribir la épica revolucionaria en tiempos de democracia. Nuestra perspectiva focaliza en las líneas hegemónicas sin descartar las residuales.

La institucionalización del testimonio, como sabemos, suele fecharse hacia la década de 1960 y en torno a los aparatos culturales de la Revolución Cubana, con la publicación de títulos como Biografía de un cimarrón(1966) de Miguel Barnet, considerado el texto fundacional del género en su vertiente etnográfica, y que será continuado por otros textos claves como Si me permiten hablar... Testimonio de Domitila, una mujer de las minas de Bolivia (1977) de Moema Viezzer y Me llamo Rigoberta Menchú (1983) de Elizabeth Burgos Debray. En estos volúmenes un informante (Esteban Montejo, Domitila Barrios de Chungara y Rigoberta Menchú) da a conocer, en entrevistas con un letrado, la particular experiencia de la comunidad a la que representa con sus luchas y desafíos. Asimismo, junto al testimonio etnográfico, comienzan a sumarse otros tipos como los testimonios guerrilleros y los testimonios periodisticos. Los primeros recogen las experiencias revolucionarias enfocadas en la lucha guerrillera y descriptas o protagonizadas por sus líderes como Pasajes de la guerra revolucionaria (1963) de Ernesto "Che" Guevara o La historia me absolverá (1953) de Fidel Castro. Los segundos corresponden a las denuncias realizadas desde cierto periodismo alternativo sobre los crímenes 
de Estado frente a una prensa oficial que los silencia; sus ejemplos más nombrados son Operación masacre (1957) de Rodolfo Walsh y La noche de Tlatelolco (1971) de Elena Poniatowska. La creación en 1970 de la categoría de "Testimonio" para los premios que otorgaba Casa de las Américas cifra la importancia de este género para la Revolución cubana.

En estos modelos se instaura una peculiar relación entre testimonio y revolución que connota políticamente a estos textos: la Revolución cubana se vuelve la matriz que da estatuto y legitima a este género como una vía eficaz para el entero proyecto político y educativo que la Revolución ideó en Cuba y que luego se extendería por el continente a través de las diversas olas revolucionarias. Surgía la imperiosa necesidad de reformar la educación para engendrar al "hombre nuevo" propuesto por Ernesto "Che" Guevara en "El socialismo y el hombre en Cuba" (1965), quien estaría capacitado para enfrentar los desafíos que se abrían con la revolución y construir el socialismo. Para ello resultaba imprescindible un entero trabajo de "concientización" que le permitiera escapar a la "alienación" enceguecedora provocada por el sistema capitalista que lo condena al sometimiento, y reconocer su lugar como agente activo de la historia en la lucha por la liberación del pueblo. Asimismo, en el ensayo Calibán (1971) de Roberto Fernández Retamar hay una clara defensa del intelectual revolucionario que se enfrenta a las fuerzas colonizadoras y neo-colonizadoras en América Latina (y una crítica a ciertas figuras del boom latinoamericano), así como una descripción de la "revolución cultural", caracterizada por las campañas de alfabetización, la universalización de la educación superior a través de la "Universidad de las Villas", el acceso de los sectores marginales -los campesinos y obreros- a la cultura y el relevo de la "universidad europea" por la "universidad americana" ("que la universidad se pinte de negro, de mulato, de obrero, de campesino").

Se apostaba a una educación que sustituyera la instrucción de corte liberal por otra de matriz marxista, en coincidencia con lo que Paulo Freire llamaría la "pedagogía del oprimido" en el libro homónimo publicado en 1968, donde define un modelo educativo que se volverá faro en América Latina con su aporte de una "pedagogía crítica", emancipatoria y liberadora, factible de desarrollar la conciencia sobre los problemas sociales. Las campañas de alfabetización de los sectores campesinos y obreros, la universalización de la educación superior, la creación de una universidad latinoamericana, y el asentamiento de una cultura "nueva y socialista" al servicio de las clases explotadas, constituyen los pilares de las reformas educativas propuestas por el nuevo estado socialista cubano.

Para esta tarea emancipatoria, no solo cubana sino latinoamericana, se precisaba oír las voces de los sectores oprimidos y conocer sus problemas, leer sus historias y sus luchas, que se vierten en el testimonio de los informantes locales. Este oficiará como el manual de estudio de esta pedagogía del oprimido, ya que allí se esparce la "experiencia" de los pueblos en contraposición a la educación formal de las escuelas del Estado. En algunas oportunidades Domitila Barrios de Chungara y Rigoberta Menchú se quejan de aquellos maestros, universitarios o intelectuales que hablan una lengua incomprensible para los sectores populares, exponen perspectivas teóricas atestadas de números, alejadas de sus realidades así como de las escuelas por su sentido reductivo sobre las historias nacionales que no los consideran. En cambio, el testimonio le ofrece al pueblo la posibilidad de "hablar" y transmitir las "experiencias" sufridas y reflexionar sobre las causas históricas de los sistemas de dominación a los que están sometidos e indagar los caminos de lucha y liberación.

El intelectual de izquierda "progresista" de la década de 1960 en América Latina fue una figura clave que rodeó las convulsiones políticas, apoyó las revoluciones y colocó a la política en un lugar central como la gran dadora de sentido, provocando el deseo de participar en la inminente transformación radical de los pueblos latinoamericanos, en un clima de gran efervescencia, de polémicas, reuniones, congresos, de creación de revistas y apertura de editoriales, de esa explosión narrativa que fue el denominado boom. Un abanico de diversos intelectuales (provenientes de la política, de la etnología, del arte, de la pedagogía, del periodismo, etc.) coopera en esta tarea de recoger las voces de los informantes, transmite estas demandas políticas al terreno cultural, literario o educativo, y autoriza, legitima e institucionaliza sus testimonios en el campo letrado. Y es en este vínculo entre el intelectual (que suele ser ciudadano, clase media, letrado y 
escriturario, hablante nativo del español, de circulación internacional) y el informante (que en general es habitante rural o de una comunidad, clase obrera, activista o dirigente, hablante nativo de alguna lengua indígena, perteneciente a una cultura oral, de circulación local) donde se dirime la política central del testimonio. Gayatri Chakravorty Spivak supo sintetizar este desafío en la pregunta “¿Puede hablar el sujeto subalterno?", criticando a aquellos teóricos postestructuralistas que, aun cuando se proponen como "profetas de la heterogeneidad" abocados a pluralizar al sujeto, terminan por subalternizarlo desde la preeminencia del sujeto europeo (1998). Jean Franco (1992), por su parte, señala "la lucha por el poder interpretativo" que el testimonio desata en tanto uno de los pocos géneros discursivos que autoriza, aun con sus limitaciones, el ejercicio del poder de la palabra del "otro" y no su "representación" como suele ocurrir en gran parte de la literatura latinoamericana, permitiendo al subalterno abandonar el lugar de objeto del enunciado para convertirse en sujeto de enunciación.

Este intelectual adopta grosso modo dos perfiles. Por un lado, el intelectual o escritor comprometido o crítico que se "compromete" con la política, con la transformación de lo real, con la revolución, que defiende una posición de izquierda, pero lo hace desde su propia autonomía y por fuera de la subordinación al Partido, de la representación del Estado (en este caso el Estado revolucionario cubano) o de los mandatos e intervenciones en su propia escritura (se pronuncia contra el realismo socialista y el arte oficial soviético). Son los escritores del boom, consagrados por los méritos de su propia narrativa experimental y vanguardista, desde la cual se proponían "revolucionar" el arte desde su interior -como el éxito editorial de Cien años de soledad de Gabriel García Márquez en 1967-.

En cambio, el escritor revolucionario privilegia la praxis política revolucionaria (y sus instituciones partidarias o estatales) a la autonomía del arte, y apuesta a un arte para el pueblo en clave "realista" y lejos de la experimentación vanguardista, en una lengua sencilla y apta para los sectores analfabetos, capaz de traducir los requerimientos revolucionarios, prefiriendo aquellos géneros de carácter social como el testimonio, la canción de protesta o el documental. El intelectual es convocado a bajar de la "torre de marfil" y a acercarse para colaborar en las diversas necesidades de la Revolución cubana: desde la toma de las armas hasta el trabajo en la zafra o en los equipos alfabetizadores. La figura del "maestro" viene a ocupar un lugar protagónico. En este contexto se revisa el concepto de intelectual que ahora será ocupado en su punto más extremo por figuras que, como la de Fidel Castro o el Che Guevara (y antes José Martí), aúnan las “armas y las letras", la "pluma y el fusil” (Gilman, 2003). También cabe señalar que por encima de estas oposiciones en ambas tendencias se percibe el impulso por refundar la literatura latinoamericana considerando el quiebre que significó la Revolución cubana.

La ruptura que el acontecimiento revolucionario significó para Cuba y para América Latina en el acontecer histórico requería una refundación cultural tan radical como lo fueron los movimientos insurreccionales y capaz de significar con eficacia la emergencia de la nueva era, de allí la necesidad de una nueva lengua, de nuevos textos, bibliotecas e imaginarios, de otros sujetos de enunciación, de relecturas a contrapelo de la historia y de los saberes, de otras verdades, de un reordenamiento de las instituciones educativas y culturales acorde a lo que venía. En este nuevo orden de cosas, el testimonio, en los tres tipos hegemónicos que hemos elegido para analizar y que desde luego de ningún modo agotan la variedad ofrecida por el género, fueron vehículos del habla y la escritura de nuevas voces, fueron canales para explorar y potenciar el acontecimiento revolucionario y medios para la circulación de otra verdad (ideológica, política, literaria, cultural, artística, etc.). Mientras en el testimonio guerrillero toman la voz los líderes revolucionarios como Fidel Castro y Ernesto Guevara, en los testimonios etnográficos son los subalternos, aquellos que la revolución se ocupará de empoderar, quienes logran hablar y ser escuchados, y en el testimonio periodístico se interpela al Estado represor indagando y mostrando sus crímenes. De este modo se dibujan las tres vigas de la maquinaria revolucionaria cuya lucha emprendida por guerrilleros y subalternos se dirige al Estado criminal.

¿En qué medida el testimonio sobre la historia reciente, producido en la caldera del Cono Sur, redefine las escrituras testimoniales? ¿Podemos hablar del surgimiento de otro modelo del género? ¿Y acaso postular 
una segunda institucionalización de éste? En este trazado ¿cuál es el giro que la ola de testimonios surgidos a partir de la experiencia de las últimas dictaduras en el Cono Sur impone al modelo que acabamos de reseñar?

La reinstitucionalización del testimonio latinoamericano en la década de 1980 supone, en primer lugar, el reemplazo de la matriz revolucionaria y sus relatos emancipatorios, esgrimidos desde las convulsiones revolucionarias, por la narrativa humanitaria levantada en las transiciones hacia la democracia, bajo el clima de derrota de la izquierda armada luego del fin de las dictaduras. Esta narrativa se articula sobre la "violación" de los "derechos humanos" por parte de los militares, y sirve de base a un reclamo de tipo ético y jurídico pero no político ideológico. Se evitaba apelar a las fuerzas enfrentadas en la década de los 70 y a la retórica revolucionaria, distanciándose tanto de los argumentos del Estado terrorista como de la izquierda radical. En esta narrativa se sustituyeron las categorías de pueblo/oligarquía o de proletariado/burguesía por la de víctimas/victimarios, consolidando una estrategia que fue empleada en los Juicios a las Juntas Militares. Se trata de una matriz de carácter performativo que no solo define una política en términos de derechos humanos, sino que también configura los perfiles y valores del testigo y de la víctima, vertebra el escenario judicial, impregna las militancias, ingresa en los museos, crea instituciones, se expande en los imaginarios sociales y se transmite a las nuevas generaciones, permea las currícula educativas, se cuela en ciertas estéticas representacionales, en especial, la del desaparecido, y es incluso apropiada por los discursos de los represores.

Todo ello implicó un notable giro cultural, ya que se quebraban las tradiciones políticas ideológicas previas al sustituirlas por los nuevos valores de memoria, verdad y justicia, y al mismo tiempo se ejercía una despolitización de lo ocurrido en los 70, visible en la figura de la "víctima inocente". Fueron los militares quienes intentaron politizar a las víctimas, hablar de la militancia guerrillera y apelar a la "guerra" para justificar el empleo del terrorismo de Estado. No obstante, el testimonio nacido al calor de la narrativa humanitaria se convirtió en un formidable dispositivo para la militancia y la lucha política. En este giro cultural no es menor el peso que adquirió la derrota de la izquierda armada en varios países de América Latina, sumada a la posterior desintegración del bloque soviético, el inicio de la perestroika y glasnost, y la caída del Muro de Berlín, que condujeron al debilitamiento de la revolución como vehículo emancipatorio y a un notable cambio en las concepciones sobre la violencia como vehículo emancipatorio.

Si por un lado este giro cultural se separaba enfáticamente del alto voltaje político de las décadas inmediatamente anteriores, por el otro, también constituye una continuidad, una recuperación y puesta en valor de una tradición latinoamericana de los Derechos Humanos de larga data y variado recorrido. Luis Roniger en Historia minima de los derechos humanos en América Latina (2018) traza un amplio trayecto de los derechos humanos en América Latina desde sus antecedentes en la Colonia hasta el presente, considerando el nivel jurídico e institucional tanto como su injerencia en la política y en los imaginarios sociales. Atendiendo a las diversas coyunturas de los países latinoamericanos, explora los avances y retrocesos de los derechos humanos, las contradicciones entre la aceptación legal y la validez real, las tensiones entre las normativas internacionales y las políticas locales, junto a los desafíos que ha enfrentado en cada oportunidad. En este itinerario marca dos momentos clave de impulso, crecimiento, expansión y fortalecimiento de los derechos humanos: por un lado, a nivel internacional, el desarrollo en torno a la Shoab y, por el otro, a nivel local, su difusión durante las transiciones hacia la democracia en varios países latinoamericanos después de las dictaduras y los conflictos armados internos padecidos durante las últimas décadas de la Guerra Fría, dando lugar a las políticas de la memoria, verdad y justicia.

Aún cuando veamos esta continuidad (con vaivenes) de los derechos humanos que Roniger delinea con un notable conocimiento, podemos advertir también que su reaparición protagónica con las aperturas democráticas implica un salto, un corte, un giro hacia la narrativa humanitaria que ahora va a ocupar un lugar hegemónico, en especial cuando confrontamos con el contexto anterior atravesado por los enfrentamientos entre los grupos políticamente radicalizados que sacudían la Guerra Fría, por las tensiones de un mundo bipolar, por las narrativas revolucionarias, por los relatos de las Doctrinas de Seguridad Nacional, por la oposición schmittiana amigo-enemigo, por las luchas revolucionarias con sus propuestas emancipadoras y las 
maquinarias represivas de estados dictatoriales -experiencias que no se ejercían en nombre de los derechos humanos-. A partir de la década de 1980, los derechos humanos van a impregnar la cultura política y sus prácticas, van a diseñar nuevos modos de militancia y nuevos canales para las demandas de justicia y en esta línea podemos emplazar la importancia que el testimonio va a adquirir y que se hace visible en el caso argentino - para citar uno de los tantos ejemplos en América Latina- con la recopilación de los relatos de los testigos por parte de la CONADEP ${ }^{3}$ en el volumen Nunca Más, así como su presencia decisiva en los juicios a las Juntas Militares.

¿Podemos situar en las posdictaduras del Cono Sur la emergencia de una era del testigo? Annette Wieviorka (1998) postula el surgimiento de la "era del testigo" ("l'ère du témoin") a partir de la Shoah y en especial con el impulso que le dio el Juicio a Adolf Eichmann llevado a cabo en Jerusalén en 1961. El advenimiento del testigo supone un interés por la memoria del genocidio que atraviesa la frontera de las víctimas, se disemina en otros países y da lugar a diversos planes para gestar y recopilar testimonios por parte de variadas instituciones y a través de múltiples soportes. Se trata de la aparición del testimonio masivo o testimonio de masas (témoignage de masse) cuyo tamaño resulta inabordable para un investigador.

También en Argentina, así como en diversos países latinoamericanos, el testigo se convierte en protagonista durante las transiciones hacia la democracia, ya que es el encargado de revelar las barbaries cometidas durante la dictadura y en buena medida desconocidas para gran parte de la población: declara ante la CONADEP (1983-1984) aportando los testimonios que formarán parte del volumen Nunca Más (1984), luego asiste al Juicio a las Juntas (1985) como testigo, y su imagen, su palabra y su escritura se esparcen a través de los medios de comunicación masiva, los films, los libros de testimonios, las marchas, los museos sobre memoria, etc.

\section{LA MATRIZ REVOLUCIONARIA: EL ESTATUTO DEL TESTIMONIO}

Entre las pautas definitorias atribuidas a esta primera forma del testimonio se destaca, en primer lugar, su adscripción a una lógica no ficcional sustentada en un código verificativo y en un pacto de referencialidad. Para Renato Prada Oropeza (1986) el testimonio se constituye a partir de un acontecimiento histórico "real", de la preexistencia de un hecho sociohistórico, que desencadena su escritura encaminada a ceñir la "verdad" de ese evento. Está enunciado por un yo (testigo, actor y juez para Jara, 1986, p. 1) en primera persona que cuenta su experiencia y se hace responsable -ética y políticamente- de sus afirmaciones, su intencionalidad explícita es la de brindar una prueba de la verdad del hecho social, es la de dar un testimonio. Este yo se configura poniendo de manifiesto su clase social, su comunidad de pertenencia, su militancia política, desde las cuales denuncia un sistema de opresión o defiende una práctica de lucha.

Su pertenencia al género non fiction presupone que el relato está sometido a un código verificativo y a un pacto referencial más allá de los errores o lagunas que pueda contener, más allá del proceso de construcción de ese "real" siempre esquivo, proclive a ser manipulado y sujeto a los vaivenes de la siempre inexacta memoria. Todas las falencias perceptibles en un testimonio no terminan de anular la pretensión de realidad y verdad que porta, aunque ya sabemos la radical dificultad que lo real supone para su aprensión por el lenguaje. El testimonio se resiste a reconocer su estatuto de artefacto y porta una notable avidez por lo verdadero. De allí que varios críticos prefieran hablar del "efecto de veracidad" (Beverley, 1987, p. 11), o la "sensación de autenticidad” (Sklodowska, 1982, p. 397) desde posiciones propias del giro lingüístico focalizadas en los procesos de edificación y ficcionalización característicos de toda representación. Las perspectivas de Hayden White vertidas en Metahistory: The Historical Imagination in Nineteenth-Century Europe (1973) advirtieron sobre los procesos de construcción del relato y de fabulación del discurso de la historia ocultos detrás de la pretensión de reflejar lo "real" histórico. Varios análisis retoman esta miradas para volcarlas al testimonio (Nofal, 2002, p. 28). 
La voluntad por latinoamericanizar el testimonio es otra de las características que lo atraviesa y lo legitima como un producto propio y original, como un dispositivo identitario. Por un lado se fragua una familia testimonial que expande y destaca la importancia del género al reunir subgéneros afines como las crónicas testimoniales, las crónicas documentalesde corte periodístico, los relatos antropológicos y etnológicos, las memorias de campaña, la novela social o indigenista, las historias de vida etnográficas, la autobiografia (popular), las memorias entre otras (Prada Oropeza, 1986; Beverley, 1987). Mabel Moraña (1997) considera que el testimonio activó aspectos ya presentes en la tradición narrativa hispanoamericana tales como las técnicas del relato de viajes, la biografía romántica, los relatos de campaña, el documentalismo de la novela social e indigenista, el ensayo sociológico, el estudio etnográfico y la elación costumbrista, así como recursos tomados de la poesía y la narrativa popular. Para destacar su sello latinoamericano, se indaga y configura un relato genealógico, una perdurable tradición de textos de carácter documental que avalaría la continuidad e importancia del género. Este género se remonta, según Prada Oropeza (1986), a las "Crónicas de la Conquista" y pone de manifiesto el evento de la Conquista como acontecimiento seminal en el que se configura una voz marginal que testimonia la opresión, el avasallamiento y la destrucción provocada por la empresa conquistadora. Esta latinoamericanización del testimonio lo presenta como un discurso eficaz para dar cuenta de los conflictos y luchas del continente, y por ello merece ser incluido en el canon literario.

Esta latinoamericanización (y nacionalización) del género se funda asimismo en su capacidad para hacer visible las diversidades culturales de comunidades marginales, por un lado, y por el otro en la voluntad por mostrar la actuación de los sectores populares en la historia como sujetos políticos, líderes, dirigentes, militantes, etc. Podemos tomar como ejemplo el gran caudal de información sobre costumbres, creencias, relatos, divinidades y rituales de religiones de origen africano, artes musicales, medicinales y culinarias, características de las diversas etnias llegadas a Cuba, la vida en los barracones de esclavos o en el monte y las cuevas del cimarrón, entre tantos otros aportes que Esteban Montejo va relatando a Miguel Barnet. O las extensas digresiones en las que Rigoberta Menchu se ocupa de presentar y explicar las ricas tradiciones y las costumbres ancestrales (los nacimientos, matrimonios, las cosechas y vínculos con la naturaleza, el tipo particular de educación, las enseñanzas orales sobre la historia, el legado de los antepasados, las pautas religiosas, medicinales, culinarias, entre tantas otras) de la cultura maya quiché en un intento por gestar un reconocimiento y valorización de los aportes culturales de su comunidad. También en la palabra de Domitila encontramos la necesidad de mostrarnos las señas particulares de la vida en las minas, de la familia minera boliviana, sus lenguas indígenas (quechua y aymara), las tradiciones del tejido, las danzas, la música, las riquezas que al Estado nacional le proveen las minas. Superar el menosprecio y el rechazo hacia estas comunidades visibles en los estereotipos racistas de los indígenas como "sucios", "haraganes" y "tontos" (Rigoberta) y del minero como "drogadicto" porque masca coca durante su trabajo o como "khoya locos" o locos de la mina como suelen llamarlos cuando se defienden de los ataques del ejército, así como transmisor de enfermedades contagiosas cuando padecen la enfermedad pulmonar de las minas llamada silicosis (Domitila). Se trata de reconocerlos como sujetos de cultura.

Además de los aportes culturales de estos sectores, uno de los intereses de las perspectivas marxistas consistió en destacar la agencia de los grupos marginales en la historia, visualizarlos no sólo como víctimas de los sistemas de dominio (conquista, colonialidad, esclavitud, dictaduras, terrorismos de estado, etc.), sino como actores en las luchas y revueltas para combatirlos, como sujetos politicos. En este sentido, la Revolución cubana como una épica del pueblo puso el foco y reconstruyó una historia de insurrecciones, levantamientos, revoluciones de los sectores populares, marginados, sometidos, esclavizados, que es posible leer en textos claves como El siglo de las luces (1962) de Alejo Carpentier y Calibán (1971) de Roberto Fernández Retamar. ${ }^{4}$

Como veremos a medida que recorramos los tres tipos seleccionados, el testimonio también se define por la presencia de una autoría ya sea individual o repartida entre el letrado y el informante cuyos complejos vínculos - de acercamiento y distancia- iluminan las disimetrías sociales y por la puesta en cuestión del concepto de "literatura", entre otras cuestiones. 


\section{1. El testimonio etnográfico}

Otra de las peculiaridades del discurso testimonial, que se hace evidente en el testimonio etnográfico, se refiere a la categoría de "autor" ya que este modelo carece de un autor tal como ha sido entendido por la literatura y en este sentido es "un reto y una alternativa a la figura del gran escritor por contraste a la narrativa del boom" (Beverley, 1987, p. 13). Presenta una doble autoría conformada por el vínculo complejo entre un letrado y un informante, una relación que se desarrolla entre la colaboración de ambos en la factura del texto hasta los conflictos que se suscitan, entre la preeminencia de una primera persona del informante dentro del texto que oculta e invisibiliza al editor y el protagonismo del editor en los prólogos y paratextos.

Tres textos canónicos han sido claves en este debate, aunque se pueden sumar otros. En Biografía de un cimarrón el antropólogo cubano Miguel Barnet graba las conversaciones con Esteban Montejo, un cubano negro de 108 años que cuenta su historia en primera persona sobre su experiencia como esclavo cimarrón y luego como soldado de la independencia. La socióloga y feminista brasileña Moema Viezzer recoge el testimonio de Domitila Barrios de Chungara, la esposa de un minero de Bolivia, convertida en dirigente del Comité de Amas de Casa desde donde lucha por sacar a las familias mineras de la pobreza en la que viven y defenderlas de las represiones y masacres acometidas por sucesivos gobiernos dictatoriales, para componer el libro Si me permiten hablar...Testimonio de Domitila, una mujer de las minas de Bolivia. En Me llamo Rigoberta Menchú (1983) la antropóloga venezolana Elizabeth Burgos Debray le realiza una serie de entrevistas a Rigoberta Manchú, una informante maya quiché, que hará un relato que abarca desde las costumbres de su comunidad hasta las persecuciones, asesinatos, masacres y vejaciones de todo tipo que estas poblaciones indígenas rurales padecieron durante el llamado genocidio guatemalteco (1981-1983), ocurrido en el período de la Guerra Civil (1960-1996).

En los tres casos se advierte una necesaria colaboración: mientras el informante es el testigo que relata oralmente -ya que suele carecer de escritura e incluso su lengua materna puede no ser el español sino una lengua indígena- su propia experiencia acontecida en el interior de una comunidad marginal, el letrado aporta la posibilidad de convertir ese relato en un texto escrito y publicable ya que conoce los códigos lingüísticos y tiene acceso a los mecanismos editoriales del circuito de la ciudad letrada. En muchos casos su voz se elimina del cuerpo testimonial y se condensa en un prólogo donde expone los procesos de edición de los testimonios.

Esta doble autoría ha desatado un vasto debate que va desde el reconocimiento de una colaboración solidaria entre el informante y el letrado hasta la advertencia sobre las disimetrias que ambos ponen en escena (síntomas de las diferencias y contradicciones sociales presentes en América Latina) o la percepción de una apropiación de la voz de subalterno por parte de la élite letrada (Prada Oropeza, 1986; Sklodowska, 1993; Beverley, 1987; Achugar, 2002; Nofal, 2002). La tensión entre las estrategias dialógicas y monológicas, entre dar la voz y apropiarse de la voz atraviesa la configuración del texto testimonial.

El informante adquiere un carácter representativo de un grupo social, se vuelve colectivo, habla en nombre de un "nosotros", señala una "polifonía ausente" (Nofal, 2002, p. 24). Domitila afirma "La historia que voy a relatar, no quiero en ningún momento que la interpreten solamente como un problema personal. Porque pienso que mi vida está relacionada con mi pueblo" (2005, p. 9). Rigoberta Menchú dice "mi situación personal engloba toda la realidad de un pueblo" (1983. p. 30). Este deslizamiento desde lo privado y personal hacia lo público y colectivo, esta intimidad pública tensiona los dos polos -objetivo y subjetivo- en que se debate este género. En este pasaje ambas hacen de su conflicto un problema estructural que delata la necesidad de un profundo cambio social, creando en el lector la sensación de formar parte de un movimiento mundial de oprimidos de todo tipo (Beverley, 1987). No olvidemos que el contexto en que se inscribe suele ser la revolución y las luchas de liberación. Aquí se delinea otra de las marcas del carácter altamente político de este género. 
El testimonio está en función de una acción político-social inmediata, de una praxis en tanto aporte a los movimientos libertarios, surge de una manifestación conflictiva "ante una experiencia de represión, pobreza, explotación, marginalización, lucha” (Beverley, 1987, p. 15) y por ello es considerado como una "narración de urgencia" y una "forma de lucha" (Jara, 1986, p. 1-2). Es una historia que se continúa, que no tiene un final como las novelas (Jara, 1986, p. 3), es una obra abierta que espera una resolución en los acontecimientos (Beverley, 1987, p. 15). Para Achugar, exhibe "la lucha por el poder" en una doble vertiente, "ya como un discurso desde el poder, ya como un discurso que intenta la desarticulación del discurso del poder" (2002, p. 15), marcando las diferencias entre un testimonio enunciado desde el margen y con valor subversivo por parte del subalterno frente a otro que se articula desde el establishment político-cultural del estado revolucionario para sostener el statu quo.

El yo que enuncia es político, ya sea el testigo que suele encontrarse como agente de una lucha (Rigoberta Menchú o Domitila Barrios) o el intelectual que hace las entrevistas y se compromete con los postulados del informante. El carácter objetivo, neutral o aséptico de la primera persona que suele caracterizar los textos científicos desaparece ante la necesidad de convencer, denunciar, tomar partido ante situaciones de extrema violencia en un contexto que ha silenciado al "otro". Los testimonios de Domitila Barrios de Chungara y Rigoberta Manchú se enuncian desde un contexto caliente de lucha y de enfrentamiento a un Estado fuertemente represor sacudido por las tensiones de la Guerra Fría en América Latina. En ambos casos se articula un yo altamente político que a través de un relato autobiográfico presenta la formación de ellas mismas como líderes de su comunidad: Domitila como dirigente del Comité de Amas de Casa-CAC y Rigoberta como líder dentro del Comité de Unidad Campesina-CUC -ambas se inscriben como parte del engranaje de las luchas libertarias-. La autobiografía oficia como columna vertebral de un relato de formación (Bildungsroman) como dirigente comunal, que incumbe tanto a los saberes prácticos de la lucha como los conocimientos intelectuales. Las dos historias constituyen un reconocimiento del indígena (y además mujer) como sujeto político e incluso como sujeto intelectual que a través del testimonio articula un relato de formación del "hombre nuevo" guevariano, de un héroe popular, de un ejemplo a seguir.

Biografía de un cimarrón opera de otro modo ya que el informante cubano Esteban Montejo, centagenario en el momento en que Miguel Barnet lo entrevista, no se ubica como líder en el terreno de lucha actual, no obstante, al decir de Elzbieta Sklodowska, la obra de Barnet "se inscribe en su integridad en el marco de la literatura cubana de la Revolución” (2002, p. 799). Por un lado, la construcción de la biografía de Montejo como un afrocubano que ha sido esclavo cimarrón y luego soldado de la independencia resulta una reivindicación de este sector marginalizado. Barnet escribe en sintonía con la ideología oficial de la Revolución cubana que "relega los conflictos raciales al pasado y concibe el futuro étnico de la isla en términos de un sincretismo armonioso" (Sklodowska, 1993, p. 83). Por otro lado, la innovadora creación de la "novela testimonio" por parte de Barnet proyecta la voluntad revolucionaria por otorgar voz a quienes participaron en la historia, pero carecen de un lugar central en ella y por releer la historia nacional a contrapelo de su versión liberal (Barnet, 1981, p. 56).

\subsection{El testimonio guerrillero}

El testimonio guerrillero ingresó al género a partir de los debates suscitados en este contexto y ante las demandas de apertura del canon y de redefinición de la categoría de "intelectual". Este modelo describe, en la mayoría de los textos, la experiencia de la lucha revolucionaria, la guerra de guerrillas en el campo de batalla. Está escrito, ya no por los dos colaboradores del testimonio etnográfico, sino por alguien que ha participado directamente en la guerra, que ha estado en el campo de combate y se hace cargo de la escritura de esta singular experiencia. Implica un desplazamiento del estatuto del historiador tradicional, burgués, que escribe desde la autonomía y profesionalización de la disciplina y por fuera de los acontecimientos, a favor de una renovada escritura de la historia hecha por sus propios protagonistas -tal como Jaume Peris Blanes 
analiza en el caso de Ernesto Guevara (2015). Es, entonces, otro camino, diferente pero complementario a los testimonios etnográficos, para dar la voz a nuevos sujetos, y entre ambos tipos de testimonio se arma el trazado de voces revolucionarias que va desde la dirigencia del ejército insurreccional y libertario hasta sujetos iletrados y subalternos de comunidades locales, a los que el triunfo bélico alfabetizará y empoderará. En la factura de este modelo aparecen subgéneros como partes de campaña, crónicas de guerra o diarios de campaña, donde se encuentra el día al día del soldado ante las inclemencias del tiempo, las largas y extenuantes caminatas por selvas o montañas, la falta de agua y comida, los enfrentamientos armados, las decisiones políticas y estratégicas, etc. Son las "narrativas guerrilleras" protagonizadas por un sujeto épico de nuevo tipo, como las denomina Juan Duchesne Winter (2010).

La épica rebelde sirve, además, como vehículo para exponer el universo simbólico de la Revolución, desde los valores e ideales que propugnan hasta los programas de reformas que llevarán a cabo luego del triunfo. Enmarcado en un decurso teleológico, el relato se asienta en un presente atravesado por la urgencia de la lucha y sus peligros cotidianos, que gestará, en el futuro colmado de expectativas, más o menos inmediato, una nueva era dirigida a la emancipación del pueblo, acabando con un pasado de siglos de sometimiento, opresión y colonialismo de los pueblos de América Latina y del Tercer Mundo.

Como explica acertadamente Jaume Peris Blanes las crónicas y textos de Ernesto Guevara no fueron escritos desde el protocolo testimonial, ya que son anteriores a su surgimiento e institucionalización, sino que se fundan en motivos propios vinculados a las perspectivas y expectativas de Guevara frente a la revolución (2015). Si Peris Blanes detecta un "anacronismo" en la lectura en clave testimonial que diluye su potencialidad revolucionaria, Victoria García (2014, p. 69) señala la constitución de un "corpus genérico retroactivo” suscitado por el boom del testimonio, que recuperaba textos que en su momento eran extraliterarios, provenientes del periodismo -como Operación masacre (1957) de Rodolfo Walsh-, o ligados a las ciencias sociales -Juan Pérez Jolote (1948) de Ricardo Pozas y Biografía de un cimarrón de Barnet- o a la militancia política -los Pasajes de la guerra revolucionaria (1963) de Ernesto Guevara.

La inclusión de estos textos sobre el fragor de la batalla en la categoría de testimonio se debió a factores tanto políticos como culturales: la consolidación de la revolución al interior de Cuba y su exportación al resto de los países de América Latina en tanto modelo a seguir, y el reconocimiento de los líderes guerrilleros como "intelectuales", obtenido luego de la pugna, las querellas y debates que rodearon la esfera literaria y cultural cubana desde los inicios del nuevo gobierno de Fidel Castro. A un motivo historiográfico se suman otros de índole política, pedagógica y proselitista en la confección de estos testimonios: si por un lado surgió la intención de "escribir una historia de nuestra Revolución” como sostiene Ernesto Guevara en el Prólogo a Pasajes de la guerra revolucionaria (1985, p. 1), por el otro era necesario describir, explicar, fundamentar y transmitir a los diversos países latinoamericanos la experiencia cubana como ejemplo a seguir y de la cual aprender.

La estructura narrativa de varios testimonios alterna dos modos de relato. La experiencia bélica situada en un presente acelerado y apremiante, encarnada en la materialidad de la lucha (el cuerpo de los soldados y sus necesidades primarias, los enfrentamientos, las bajas y los heridos, etc.) y en los valores del combate (valentía, resistencia, compañerismo, fe revolucionaria, etc.). Y una perspectiva más amplia, de carácter teórico y programático, desplegada hacia un horizonte futuro, donde se analizan las causas y se exponen los argumentos (colonialismo, imperialismo, latifundios, monopolio, capitalismo, dependencia, subdesarrollo, etc.) que justifican la Revolución y sus programas de reformas (educación y alfabetización, reforma agraria, nacionalización de las empresas, reforma del Estado, etc.). Lo que implica la alternancia entre una mirada parcial, focalizada desde un solo ángulo, dirigida a un fragmento, y una perspectiva panorámica, de gran angular, restitutiva de una totalidad.

Dentro del extenso corpus existente, solo vamos a detenernos muy brevemente en dos textos: Pasajes de la guerra revolucionaria de Ernesto "Che" Guevara (1963) y La historia me absolverá, pronunciado por Fidel Castro en el juicio del Moncada, el 16 de octubre de 1953, en el que fue acusado y condenado a una pena 
de 15 años de cárcel por su participación en los asaltos a dos cuarteles militares, aunque luego fue puesto en libertad tras una amnistía concedida por Fulgencio Batista en 1955, que le permitió a Castro trasladarse a México, antes de regresar a Cuba en el barco Granma en diciembre de 1956 para dar inicio a la empresa revolucionaria. Debido a que no hubo una grabación de su testimonio en el juicio, él mismo lo reconstruyó para publicarlo como el manifiesto del Movimiento 26 de Julio.

Pasajes de la guerra revolucionaria de Guevara es uno de los ejemplos cabales del testimonio revolucionario ya que relata la saga inaugural de la liberación de Sierra Maestra por parte del Ejército Rebelde desde la salida del puerto de México en el Granma para arribar a las costas cubanas el 2 de diciembre de 1956 -sellando el origen utópico de un nuevo tiempo histórico- hasta la victoria final. Acuña el valor de las armas como vía de emancipación de los pueblos y defiende la violencia guerrera en su capacidad performativa para liberar América Latina de sus varias e históricas sujeciones, tanto en su apuesta al foco guerrillero como en su defensa de la revolución permanente. El relato, o lo que Juan Duchesne Winter llama la "guerrilla narrada" (2010), está a cargo del Comandante Che Guevara, quien legitima la "verdad" testimonial por ser testigo y haber participado en los acontecimientos como uno de los actores principales en su calidad de líder.

Este testimonio expone la emergencia de un nuevo universo simbólico, el de la revolución, a través de la configuración del guerrero y sus experiencias bélicas en la Sierra por un lado, y por el otro, por medio de los análisis políticos de los sistemas de opresión que aquejan a Cuba y a los demás países latinoamericanos y de los programas revolucionarios que permitan su liberación. Duchesne Winter (2010) ha analizado los rituales de aprendizaje y formación del soldado del Ejército Rebelde quien debe superar la prueba de resistencia y la gran prueba de fuego. Enfrentar la inclemencia del medio, el hambre, la sed, el cansancio, las interminables caminatas y la falta de calzado entre otras cuestiones; sortear la tentación de abandonar, rendirse, desertar o huir del campo de batalla y traicionar a sus camaradas; desarrollar un talante estoico, austero, viril, valiente, mostrando dignidad ante la muerte, disposición al sacrificio de la propia vida por una causa mayor, auxilio al débil y compañerismo, constituyen algunos peldaños en la formación meritocrática del guerrero heroico. La narración como un encadenamiento de pruebas que el soldado rebelde enfrenta destaca el protagonismo de la lucha armada como eje central del universo revolucionario para la perspectiva de Guevara. En una línea similar, para Peris Blanes (2015) el dispositivo de la narratividad está dado por el nacimiento y construcción de una nueva subjetividad, la del combatiente rebelde, cuyo desarrollo gradual se afianza a través del ejercicio progresivo de la disciplina (cohesión, orden, organización, moral combativa, compañerismo, etc.) en el campo de batalla, cuyos logros lo convierten en modelos ejemplar a imitar, permitiendo la "emulación" tanto dentro de Cuba como en otros países. Pasajes de la guerra revolucionaria funge como un manual en el cual las escenas ilustrativas y los errores aleccionadores sirven como material de aprendizaje y guías para su reproducción.

Resulta evidente la presencia de la matriz revolucionaria en La historia me absolverá, en la cual Fidel Castro -como testigo de primera mano y sin intermediarios- describe la praxis guerrillera en los frustrados asaltos a los cuarteles Moncada y Carlos Manuel de Céspedes, en Santiago de Cuba y Bayamo respectivamente (26 de julio de 1953), de la mano de la "rebeldía y el heroísmo de nuestra juventud" (2007, p. 22). Proyecta, además, una propuesta ideológico-programática de los cambios que la revolución llevará a cabo a través de las cinco leyes revolucionarias y los seis puntos a considerar: "el problema de la tierra, el problema de la industrialización, el problema de la vivienda, el problema del desempleo, el problema de la educación y el problema de la salud del pueblo; he ahí concretados los seis puntos a cuya solución se hubieran encaminado resueltamente nuestros esfuerzos, junto con la conquista de las libertades públicas y la democracia política" (2007, p. 38).

No obstante, me interesa apuntar una lectura a contrapelo, focalizada en el escenario judicial que dio origen al texto y que nos presenta a un testigo frente a un tribunal de justicia pronunciando un alegato de defensa si bien Castro es el acusado, pide ser su propio abogado defensor ya que es licenciado en Derecho Civil-. Este marco judicial no es usual ni central en este primer modelo de testimonio, pero sí lo será y de modo notable en el testimonio inaugural de la segunda ola cuando, por ejemplo, los testigos declaren ante el tribunal en el 
Juicio a las Juntas militares en Argentina. Esta confrontación ilumina las diferencias entre ambos contextos. Castro disputa la legitimidad de la justicia estatal atenazada y envilecida por la dictadura de Batista y ello le sirve como fundamento para invocar la legitimidad de ejercerla por parte de la revolución en base al derecho de insurrección contra los tiranos. Este derecho a la resistencia frente al despotismo o derecho a la rebelión que Castro defiende con múltiples ejemplos a lo largo de la historia se vincula estrechamente con el concepto de "violencia justa" esgrimido desde diversos espacios, desde las propuestas de Franz Fanon hasta los argumentos de la Iglesia del Tercer Mundo y la Teología de la Liberación, que servirá como argumento legitimador de la lucha armada revolucionaria (Basile, 2018). De este modo, la matriz revolucionaria no solo se encuentra en el nivel descriptivo de la épica de los asaltos a los cuarteles o de los puntos del futuro programa revolucionario, sino que interviene en las vigas que sostienen la institución judicial, disputando el uso mismo de la justicia al cuestionar y rechazar al tribunal, y otorgar a la revolución el derecho a ejercer la justicia, ya que "la revolución (es) engendradora de derecho" (Castro, 2007, p. 76). Como testigo que testimonia en el vacío de la justicia de un gobierno dictatorial y en los prolegómenos de la revolución, Castro constituye el envés del testigo en los juicios a los dictadores militares convocados por el gobierno democrático argentino, un testigo que sólo encontrará justicia en la revolución o en la absolución de la historia (p. 90).

\subsection{El testimonio periodístico}

Se trata de testimonios escritos por periodistas (o por quienes adoptan este rol en la escritura) que asumen el riesgo de averiguar, describir y denunciar un crimen cometido por el Estado que ha sido silenciado u ocultado por la prensa oficiosa y ha quedado impune por la justicia. Operación masacre (1957) de Rodolfo Walsh o La noche de Tlatelolco (1971) de Elena Poniatowska son dos de los ejemplos paradigmáticos del género. El primer texto revela los asesinatos clandestinos de cinco civiles cometidos el 9 de julio de 1956 en el basural de José León Suárez (Buenos Aires) por el aparato policial y con la anuencia de las más altas jerarquías del Estado de la dictadura cívico-militar autodenominada Revolución Libertadora, luego del fracasado levantamiento cívico-militar de inspiración peronista liderado por el general Juan José Valle contra dicha dictadura. En el segundo texto Poniatowska reúne y recopila diversas voces, versiones y documentos sobre la feroz represión por parte del ejército y la policía enviados por el presidente constitucional de México Gustavo Díaz Ordaz hacia el movimiento estudiantil congregado en una manifestación el 2 de octubre de 1968 en la Plaza de las Tres Culturas, ubicada en el Conjunto Urbano Nonoalco Tlatelolco, en Ciudad de México. Se les ha dado diversos nombres tales como "testimonio noticiero" (Sklodowska, 1992), "relato documental o testimonial” (Amar Sánchez, 1992), ente otros.

Es el género policial el entramado narrativo que Rodolfo Walsh elige para desplegar su relato (el periodista como detective y el itinerario de su investigación), tal como analiza Amar Sánchez en su estudio El relato de los hechos. Rodolfo Walsh: testimonio y escritura. Pero, aclara Amar Sánchez, más que los pasos del detective del policial clásico quien indaga la verdad a través de un método lógico, racional y deductivo, Walsh seguiría la línea del policial negro norteamericano donde la verdad solo se descubre exponiendo el cuerpo, porque no se encuentra en la cabeza del detective sino afuera, en la sociedad violenta y peligrosa. Incluso frente a este género, Operación masacre ejerce una torsión ya que indaga en un crimen cometido por el Estado, lo que supone un profundo desorden en las reglas de la política o del juego democrático, una inversión de los actores: mientras los victimarios son agentes del Estado que involucran a los más altos mandatarios, las víctimas son los ciudadanos, de modo tal que quienes están a cargo de implementar la justicia y cuidar a la población, en realidad son los delincuentes que persiguen a sus víctimas y les niegan la protección de la justicia. Cuando se trata de un Estado que delinque, no hay justicia capaz de acusar y restablecer la seguridad ciudadana. La ley y la justicia pasan, entonces, a mano del periodista quien se ocupa de describir los hechos, señalar a los culpables, exhibir la verdad, denunciar a la justicia, y la única reparación posible es la escritura y publicación del texto (Amar Sánchez, 1992, p. 125-156). 
El pasaje de una noticia periodística al libro testimonial implica en Operación masacre una serie de transformaciones que conducen a narrativizar el acontecimiento, al desmontaje de la pretendida objetividad del periodista y a la toma de partido frente a los hechos en confrontación polémica con otras perspectivas, lo que acentúa la politicidad del testimonio (Amar Sánchez, 1992, p. 77-121). Se suele vincular el texto de Walsh con el surgimiento del Nuevo Periodismo y la non fiction estadounidenses que se proponían renovar el viejo y desgastado periodismo a través de técnicas literarias, pero también se advierte el carácter fundacional de Operación masacre (1957) ya que se publica varios años antes que $A$ sangre fría (1966) de Truman Capote, texto considerado inaugural de la non-fiction-novel. Resulta interesante, por otro lado, la comparación que Eduardo Jozami establece, marcando similitudes y diferencias, entre la renovación que Walsh opera sobre el periodismo y los cambios que el nuevo periodismo argentino de los años sesenta está llevando a cabo, considerando especialmente el semanario Primera Plana, fundado por Jacobo Timerman (Jozami, 2013, p. 181-203). Sea cual fuere la conexión de Walsh con estos desarrollos anteriores y ulteriores, lo que sí resulta significativo para nuestro argumento es su postura sobre los cambios en las concepciones de la literatura a partir de su militancia en el peronismo revolucionario y de su viaje a Cuba que lo conecta con los acalorados debates sobre el lugar y la índole de la literatura en la revolución y le permite participar del auge del testimonio. Las sucesivas reescrituras de Operación masacre (1957, 1964, 1969 y 1972) van marcando su notable giro político desde su temprana participación en el grupo nacionalista de derecha "Alianza Libertadora Nacionalista" hasta su acercamiento al peronismo para finalmente formar parte de Montoneros. En su cuarta edición señala la continuidad de la Resistencia del peronismo entre el frustrado levantamiento de Valle reseñado en su libro, reprimido con los fusilamientos cometidos por la dictadura del general Aramburu de 1956, y la ejecución del general Aramburu en 1970 por Montoneros cuya mención se agrega en un nuevo capítulo incorporado bajo el título "Aramburu y el juicio histórico". En esta línea, Operación Masacre se convierte en un texto fundacional de la Resistencia peronista según Jozami (2013, p. 75). Esta fuerte politicidad que va adquiriendo y profundizando el libro junto con el carácter fundacional de un nuevo género, el testimonio periodístico, atribuido a Operación masacre, constituyen para Rodolfo Walsh, a medida que pasa el tiempo y él se compromete con la Revolución cubana y con la militancia revolucionaria peronista, signos del tipo de literatura que los convulsionados tiempos del presente de los setenta requieren.

En una entrevista que le hace Ricardo Piglia en 1970 propone cambios en la literatura para poder intervenir en las luchas del presente, en los “procesos de revolución”, ante el “esplendoroso final” de la ficción. Propugna una literatura fuertemente articulada con la praxis política, creada a partir de documentos y con una función de denuncia. Walsh participó, además, en los acalorados debates sobre los nuevos rumbos de la cultura y la literatura, viajó en varias ocasiones a La Habana invitado por el gobierno e incluso ofició como jurado de los premios de Casa de las Américas en tres ocasiones, una de las cuales fue el premio inaugural de 1970 sobre Testimonio, entre otras tareas en apoyo a la revolución (Jozami, 2003, p. 101-125). De modo que Operación... fue capturado y releído en clave testimonial y revolucionaria.

Una de las apuestas cruciales de La noche de Tlatelolco (1971) de Elena Poniatowska consiste en certificar la feroz represión de los estudiantes sucedida el 2 de octubre de 1968 en la Plaza de las Tres Culturas, en afirmar su existencia frente al silencio, la minimización y la tergiversación de los hechos por parte del Estado y de la prensa mexicana. La escritora y periodista se enfrenta a lo que constituye el grado cero del testimonio: reconstruir paso a paso el acontecimiento desde el cruce de versiones contradictorias sobre lo ocurrido, haciendo ostensible las dudas, las ambigüedades, las interrogaciones, lo que impide terminar de describir e interpretar lo acontecido en su totalidad y arribar a una verdad completa, pero que asimismo muestra en esta fragmentariedad el papel de desinformación de la prensa. Una polifonía de voces, además de reconstruir el momento del ataque a los estudiantes, recorre otros temas que iluminan el contexto, tales como los complejos vínculos generacionales entre padres e hijos que se atreven a la militancia, la libertad sexual, el pelo largo y la minifalda; las diferencias de esta protesta respecto al Mayo francés; los conflictos dentro del movimiento estudiantil entre los "teóricos" y los "brigadistas"; las dificultades para sumar a los obreros 
y campesinos en las propuestas; la participación de las mujeres en la militancia y en la guerrilla, la vida en la cárcel de los presos políticos, las posiciones adoptadas por la Iglesia, las Olimpíadas que tendrían lugar poco después, los acercamientos y diferencias con otras revoluciones como la cubana y las mexicanas, los vínculos con la conquista de México desde la "visión de los vencidos", entre otras cuestiones.

El "silencio" es un tema recurrente en la literatura de Elena Poniatowska tal como se evidencia en el título mismo de otro de sus libros Fuerte es el silencio y en la insistencia en dar la palabra al otro que registran sus textos. La proliferación, el montaje y la polifonía, tres procedimientos literarios, se ocupan de llenar ese silencio con la multiplicidad y variedad de testimonios, diálogos, noticias de diarios, documentos de diferentes fuentes, fotografías, poesías, textos literarios, a cargo de diversas voces -estudiantes, profesores, soldados, policías, enfermeros, actores, obreros, campesinos, presos, amas de casa, vecinos, familiares de las víctimas, funcionarios del Estado, periodistas locales e internacionales, comerciantes, profesionales, religiosos, atletas, voces anónimas, etc.-, algunas "discordantes" como las llama Sklodowska (1992, p. 158). Mientras la proliferación, un tropo barroco, al sumar documentos insiste una y otra vez -variando los ángulos- en la existencia del acontecimiento ante la vacuidad informativa; el montaje, un tropo vanguardista que al decir de Peter Bürger procuraba unir arte y vida, abandona la pretensión de crear una obra total y cerrada capaz de representar lo real como un todo coherente, a favor de una textualidad fragmentaria, discontinua y polifónica, que yuxtapone escenas y voces sin oculta su carácter de artefacto construido. La polifonia de voces como una presencia simultánea de diversos puntos de vista en disputa -que Mijaíl Bajtín supo explicarnos- se convierte en la proyección ideal de uno de los mandatos centrales del testimonio de dar la voz en el escenario de "la lucha por el poder interpretativo" señalada por Jean Franco (1992). Este collage logrado a partir de la proliferación, el montaje y la polifonía genera movimiento, espacialidad, confusión de voces, introduciéndonos en el fragor del acontecimiento, ya que los fragmentos parecen recortados in medias res del contexto y suelen estar precedidos por cánticos, consignas, carteles, porras, volantes y pancartas de las manifestaciones. Otro de los factores que completa la escena e interpela al lector, es la apelación a los afectos y emociones, en especial los que provienen de las madres buscando incansablemente a sus hijos por las morgues, los hospitales y las cárceles.

Si los testimonios etnográficos nos introducen en las comunidades subalternas con sus actuales luchas, si los testimonios guerrilleros nos revelan las vigas maestras de las olas revolucionarias narradas por sus líderes, en cambio el testimonio periodístico nos interna en las entrañas del Estado criminal y sus delitos políticos, sea en dictadura o democracia. Cada uno de estos modelos adopta el entramado de un género. El testimonio periodístico recupera el policial en tanto introduce la búsqueda de la verdad y el ejercicio de la justicia, mientras el testimonio guerrillero recobra las crónicas y los diarios de campaña, que nos enseñan los avatares de la lucha, y la autobiografía junto a los relatos de aprendizaje, en tanto ejemplos de la formación de líderes populares, se enhebran en los testimonios etnográficos.

El aporte fundamental del testimonio periodístico es mostrar esa otra verdad que es silenciada, que procura ocultarse, tergiversarse o borrarse, consiste en denunciar los crímenes políticos del Estado contra los movimientos de resistencias como los dos casos de Walsh y Poniatowska. Se propone esgrimir otro tipo de justicia que no reside en los Estados. Contra este Estado autoritario y criminal, contra una justicia al servicio de los intereses de los poderosos y contra un periodismo oficial y cómplice se van a levantar los diversos movimientos insurgentes en América Latina. Podríamos decir que con el testimonio periodístico ingresa otro de los actores fundamentales que configuran la arquitectura revolucionaria: la destitución del Estado criminal será el objetivo de la lucha revolucionaria protagonizada por la guerrilla y los subalternos. De este modo, una íntima, profunda y necesaria conexión se establece entre los tres tipos de testimonio que hemos reseñado: configuran el brazo escriturario de la práctica revolucionaria. Y lo hacen no sólo a través de los temas que introducen sino confrontando con la institución literaria hegemónica, a la que consideran de carácter burgués, sólo accesible a una porción letrada de la sociedad latinoamericana y distanciada de la praxis política. A ella le exigen: la apertura de la literatura hacia otros autores y voces (subalternos, informantes, líderes y 
combatientes revolucionarios, periodistas, etc.), la inclusión de géneros literarios marginales y populares que como el testimonio, el policial, el periodismo, las autobiografías o los diarios de campaña no pertenecen a la "alta" literatura, y el compromiso con los movimientos libertarios del presente para finalmente terminar con los modos de opresión e injusticia sobre vastos sectores de la ciudadanía.

\section{LA NARRATIVA HUMANITARIA: EL NUEVO ESTATUTO DEL TESTIMONIO}

Con la apertura democrática en la Argentina, el testimonio esgrimido desde la narrativa humanitaria se volverá hegemónico, si bien ya había comenzado a gestionarse durante la dictadura impulsado por diversos organismos de Derechos Humanos y por las víctimas y sus familiares. Para los sobrevivientes, en especial aquellos que se encontraban en el exilio, en un primer momento no les resultó sencillo pasar del discurso político de matriz revolucionaria usado en la militancia hacia el lenguaje de los derechos humanos, pero debieron hacerlo para poder radicar las denuncias en diversos foros que requerían ese formato de discurso.

Nos preguntamos, entonces, cuáles son las marcas de este tipo de testimonio que está dispuesto a revelar la maquinaria del terrorismo de Estado y que opta por dirigirse al Estado para reclamar justicia empleando argumentos fundados en los derechos humanos. Un giro que privilegia la memoria de los genocidios y las víctimas bajo el clima de derrota de los movimientos insurgentes. Tanto Enzo Traverso en "Historia y memoria. Notas sobre un debate" (2007) como Hugo Vezzetti en Sobre la violencia revolucionaria (2009) establecen una distinción entre las memorias de las glorias nacionales, centradas en los héroes, sustentadas en los relatos de guerras y victorias, que procuran unificar a los ciudadanos en el espacio sacro de la Nación, y aquellas memorias focalizadas en los crímenes y las víctimas, narradas por los testigos y sobrevivientes, que han adquirido visibilidad a partir de los testimonios de Primo Levi en torno al Holocausto y se resisten al tono de exaltación y unificación de las memorias nacionales. En esta línea, los testimonios de esta segunda ola brotada en nuestro continente van a vincularse a la tradición surgida en torno a la Shoah, recuperando categorías y debates para ajustarlos o mostrar sus diferencias con las experiencias argentinas y latinoamericanas. Pero también podemos preguntarnos en qué medida el diálogo con la propia tradición testimonial latinoamericana influirá en la factura de este segundo testimonio.

Una aproximación al nuevo estatuto de este testimonio -que en esta ocasión no podemos abordar en profundidad dada la breve extensión de un artículo- requiere revisar, en primer lugar, los cambios en el valor de la "verdad", en el código verificativo y en la capacidad referencial, que se volvieron centrales para el develamiento de la "verdad" sobre el terrorismo de Estado, en especial con la recopilación de testimonios encarada por la CONADEP y la publicación del Nunca Más en 1984, donde se forja el testimonio sobre la desaparición de personas (Basile, 1998), que podemos considerar como el grado cero de este segundo modelo, de carácter constituyente, que luego se irá transformando a lo lago de diversas coyunturas. Además de describir el mecanismo de la desaparición, la estructura y el funcionamiento de los Centros Clandestinos de Detención y el accionar de los represores, estos testimonios se convierten en pruebas para la justicia de cara al inminente Juicio a las Juntas de 1985 (Crenzel, 2008). El primer modelo de testimonio que vimos, en especial el testimonio periodístico, carece de final en un contexto gobernado por un Estado criminal y una justicia cómplice, por ello se estructura como una obra abierta que espera ser resuelta por la victoria revolucionaria. En cambio, en este segundo modelo, el testimonio enunciado en democracia se dirige al Estado y a la Justicia buscando una reparación. Hay un particular cambio en los vínculos del testimonio en relación con la justicia y con la política, que pone en evidencia un corrimiento desde lo político hacia lo jurídico como espacio donde efectuar las demandas y obtener respuestas.

El psicoanálisis y la historia van a revisar o poner en cuestión este alcance y poder de la "verdad" del testimonio desde diversas perspectivas. El psicoanálisis explora las fracturas ocasionadas por el trauma sobre la integridad y coherencia del testimonio -lo que lejos de quitarle valor de verdad, exhibe el impacto de la violencia en la misma quebradura del lenguaje y de la narratividad (Kaufman, 2000; 2006). Desde el discurso 
de la historia se va a poner a prueba la legitimidad del testimonio como fuente fiable de datos. Han sido múltiples y abundantes las aproximaciones sobre las tensiones y encuentros entre testimonio e historia, entre la memoria con sus lagunas y el rigor científico de la historia, entre la apelación a las emociones y el régimen del pensamiento, entre la experiencia inmediata y la reflexión distanciada. Pero el testimonio ha llegado para quedarse y su valor como fuente resulta difícil de negar. Lo que acontecimientos como los genocidios provocaron fue la puesta en crisis de la figura tradicional del historiador que se acerca al estudio de un evento "caliente" desde la distancia crítica y la pretensión de objetividad, ya que estos sucesos interpelan no solo su capacidad intelectual sino también emocional, psíquica, corporal y ética -entre tantísimos ejemplos, véanse estos debates en Wieviorka (1998) y en Sarlo (2005).

El estatuto del testigo es otro de los elementos que varía notablemente en esta segunda ola. Frente a los testigos del primer modelo revolucionario (el informante, el líder guerrillero y el periodista), la figura privilegiada en este segundo modelo es, sin duda, el sobreviviente cuyo perfil fue cambiando desde la sospecha por su colaboración con los represores y la traición a sus compañeros (Longoni 2007) hasta el reconocimiento de su carácter de víctima del terrorismo de Estado y la valoración de sus aportes como testigo (Guglielmucci, 2017; Vecchioli, 2001). Entre quienes declararon ante la CONADEP y en el Juicio a las Juntas también se encuentran familiares, testigos involuntarios (vecinos, empleados de la morgue y de cementerios, etc.) y represores. En ocasión de diversos genocidios resulta necesario considerar los testigos de las segundas y subsiguientes generaciones que involucran el ejercicio de la transmisión intergeneracional (Basile y González, 2020), así como el "testigo de testigos" que permite el "testimonio sin testigos", el pasaje de la "era del testigo" a la del "hacerse testigo" (Perassi 2015; 2017).

Un caso particular lo constituye la segunda generación argentina que se caracteriza, en muchos casos, por portar una doble memoria: la memoria de los padres, heredada y parcialmente ajena que ellos se proponen averiguar (desde la búsqueda de los huesos hasta la indagación sobre sus ideales políticos, su militancia, sus gustos culturales, sus afectos, etc.), y la memoria de la infancia, propia y experimentada, ya que ellos, en su mayoría, han padecido directamente el terrorismo de Estado a través del secuestro de los padres, del allanamiento de la casa, de la infancia clandestina, de las visitas a la cárcel, de la orfandad y la convivencia familiares, del nacimiento en cautiverio, de la apropiación por los represores, del exilio, etc. (Basile 2019a y 2020d).

Los testigos y sus testimonios van configurando corpus textuales específicos, con sus propias temporalidades y desarrollos, formando así la familia testimonial de esta segunda ola: los testimonios de mujeres, del exilio, carcelarios, de ex guerrilleros y de represores, entre otros.

Una tercera característica distintiva de este modelo es la proliferación, diversificación y variación de los testimonios. Por un lado, las sucesivas ediciones con abultadas tiradas del Nunca Más convertido en un best seller, su circulación a través de redes transnacionales de derechos humanos y las réplicas de textos similares en diversos países latinoamericanos (Brasil: Nunca Mais; Uruguay, Nunca Más, Guatemala: Nunca Más, entre tantos otros) ponen en evidencia la difusión masiva de este texto que empodera al testimonio como el género privilegiado y a los testigos como voces autorizadas para explorar los Crímenes de Lesa Humanidad cometidos en América Latina en la historia reciente. Por otro lado, estos testimonios, en especial aquellos vertidos en el Juicio a las Juntas, fueron repetidos en diferentes escenarios definidos por diversos medios, soportes, canales y espacios como la fotografía, la voz o la imagen grabada, la prensa escrita o la televisión, los textos escolares. Parafraseando a Jürgen Habermas (2000), podemos decir que se desató un vasto uso público del testimonio desde diversos lugares y sentidos, un uso por parte de las agrupaciones de Derechos Humanos, por los museos, monumentos, instalaciones, por el sistema educativo, en las marchas, escraches y conmemoraciones, un uso para demandar otros derechos, protestar por otras violaciones. Esta plasticidad del testimonio de matriz humanitaria, su flexibilidad para adaptarse a diversas coyunturas, su maleabilidad es también su riesgo. Finalmente: ¿Qué es aquello que podemos considerar un testimonio per se? Además de las declaraciones orales o escritas realizadas por los testigos, también la fotografía, los objetos y los edificios convertidos en 
sitios de memoria (ex Centros Clandestinos de Detención, dependencias policiales, etc.) se han convertido en evidencias del terrorismo de Estado. Cada tipo de testimonio configura un diverso modo de narrar o representar el pasado reciente desde sus propios lenguajes, de abordar y trabajar la memoria, de afrontar el desafío de expresar la violencia radical; un reto atravesado por perspectivas gnoseológicas, comunicacionales, éticas y estéticas, por el peligro de la banalización, de la estetización o de la espectacularización de las barbaries (Friedlander, 2007; Feld, 2010) y por las tensiones entre un uso informativo y otro comercial del horror (Feld, 2015).

Las tipologías también constituyen otra variación entre uno y otro modelo. Mientras los tres tipos de testimonios de matriz revolucionaria que hemos considerado dibujan el vínculo entre los protagonistas las clases explotadas, los revolucionarios y el Estado criminal- de la lucha de la izquierda insurgente, en este caso a los testimonios de víctimas sumamos aquellos de los victimarios y ambos apuntan a las dos principales fuerzas enfrentadas en la historia reciente. No obstante el carácter de testigos de los perpetradores resulta problemático. Las declaraciones de las víctimas servían para develar, conocer y probar la "verdad" de la maquinaria del terrorismo de Estado, en cambio los testimonios de los represores, en la enorme mayoría de los casos, no funcionan como un dispositivo verificativo ni judicial. Despliegan una paradoja: no testimonian lo acontecido, no procuran revelar una verdad ni aportar información, sino que ocultan, silencian, encubren y niegan, o solo describen torturas y "vuelos de la muerte", reconocen, se jactan y justifican el haber cometido algunas acciones más o menos atroces "como en toda guerra", pero no dan información que permita recuperar los cuerpos de los desaparecidos ni entregan las listas de los niños apropiados. Hablan pero no testimonian, hablan para testimoniar el pacto de silencio. Seamos más radicales: ¿podemos considerar la existencia de un represor testigo? Y en caso afirmativo ¿cuál debería ser su testimonio, qué debería aportar? ¿O el represor debe correrse de su historia y actuación anteriores para adquirir la autoridad de testigo?

También en este caso podemos advertir el pasaje desde un relato de matriz política hacia otro en clave de derechos humanos. La narrativa triunfalista de los primeros tiempos fundada en la Doctrina de Seguridad Nacional hacía de los militares los salvadores y mártires de la patria ante la amenaza desintegradora del comunismo. En cambio la narrativa trágica, que adviene hacia 1995 ante los reveladores testimonios sobre los "vuelos de la muerte" del capitán Adolfo Scilingo y del ex suboficial del ejército Víctor Ibáñez que desacreditaban la imagen de salvadores y mártires, recupera el lenguaje de los derechos humanos convirtiendo a los militares en víctimas del terrorismo subversivo (Salvi 2012; Feierstein, 2007).

Esta línea se continúa en la segunda generación de los hijos de represores, cuyos testimonios también adoptan la matriz humanitaria, tanto aquellos que defienden a sus padres como quienes los acusan (las y los hijas/os desobedientes). Si bien los perpetradores y los hijos que los defienden se reapropiaron de la matriz de los derechos humanos, sus propuestas tenían otros fines completamente diferentes: evitar los juicios, obtener beneficios para los presos, mejorar su imagen ante el desprestigio social, defender su actuación en la "guerra antisubversiva", reposicionar a las instituciones castrenses, fraguar políticas de impunidad, perdón y reconciliación, entre otros. Fue una estrategia de lucha en los planos culturales, políticos y judiciales que eligió disputar con las armas del adversario. Pero en la base de este giro táctico siguen actuando las tradiciones propias de la cultura militar como las gestas gloriosas del pasado, los imaginarios de la Nación y de la Familia, los valores castrenses considerados ejemplares y edificantes, y es en esta genealogía que se procura injertar la "lucha contra la subversión" como un triunfo más. En cambio en el colectivo Historias Desobedientes: Familiares de genocidas por la Memoria, la Verdad y la Justicia (2017) sí estaría presente la narrativa humanitaria al servicio de las luchas por la memoria, la verdad y la justicia e incluso sus miembros han solicitado al Poder Judicial poder declarar en los tribunales como testigos en las causas contra sus padres (Bartalini, 2018, pp. 160-161; Basile, 2019a; 2019b; 2020b).

Si bien en estos testimonios es la narrativa humanitaria la que determina, como ya adelantamos, el carácter de víctima inocente que ha padecido la violación a sus derechos humanos, luego van surgiendo variantes que recuperan la militancia, que exploran la injerencia del racismo y del antisemitismo o del género en 
la maquinaria represiva, que describen los avatares en el exilio, que establecen vínculos con la Shoab o genealogías con anteriores genocidios en América Latina, entre otras cuestiones. El uso, en el presente, del testimonio por diversas clases de víctimas vinculadas a otras formas de violencia (femicidios, gatillo fácil, narcoviolencia, migrantes, racismo, etc.) habla de la actualidad y potencia del género.

\section{Proyecciones del testimonio en el arte y la literatura}

Otro momento de gran proliferación del testimonio lo encontramos en las diversas propuestas de la literatura y del arte, que suelen partir de una base testimonial para luego intervenirla. Solo nos vamos a detener en algunos ejemplos.

El primer modelo de testimonio surgido de la matriz revolucionaria desató un vasto movimiento de la crítica tendiente a cuestionar la institución literaria por su carácter burgués y letrado que dejaba fuera gran parte de las producciones de comunidades cuya lengua madre no eran el español, que no empleaban la escritura, ni tenían acceso al circuito de publicaciones radicado en las urbes. Se propuso, entonces, una concepción “amplia de la literatura" (Prada Oropeza, 1986, p. 18) para poder incluir el testimonio, en especial el etnográfico, dentro de la literatura latinoamericana y reconocerlo como un "hecho literario" (Sklodowska, 1992). El vínculo del testimonio con la institución literaria ha sido conflictivo y complejo: en tanto género subversivo interpela el estrecho y clasista canon al mismo tiempo que se solicita su inclusión institucional en la literatura latinoamericana. En tanto género híbrido es situado alternativamente dentro de la novela, en el espacio extra literario o en el margen de la institución literaria. No obstante, en un movimiento centrípeto, la crítica procuraba una y otra vez incluir estas textualidades, reacias a la ficción y poco atentas a las dimensiones estéticas de la escritura, en la categoría de lo literario para darles legitimidad, hacerlas visibles, configurar un público lector que las consumiera, es decir para darles el derecho de ingreso a la prestigiosa literatura latinoamericana y a su canon, al tiempo que cuestionaba su carácter ilustrado, urbano, escriturario, mono lingüista, que poco reflejaba la realidad de América Latina. Como vimos, estas propuestas se vinculan a los nuevos proyectos pedagógicos surgidos en torno a la Revolución cubana.

En cambio el testimonio actual, que ya ha conseguido un lugar propio, autónomo, consolidado y reconocido, con modalidades y circuitos específicos, no se interesa ya por el reconocimiento de la literatura y ahora es la literatura la que lo recupera como un material con el cual trabajar, experimentar, intervenirlo, desviarlo. Si en los 60 el testimonio constituía una alternativa a la literatura del boom latinoamericano y entre ambos parecía existir un abismo de diferencias en cuanto a las estéticas (realismo socialista versus realismo mágico o maravilloso), en el modo de articularse con la revolución (escritor revolucionario versus escritor comprometido) y en los circuitos de producción y circulación (marginales y hegemónicos), en cambio ahora hay diálogo e intercambios.

Asistimos hoy a un movimiento centrífugo por el cual el testimonio se instaura como plataforma para luego fugar de su pacto de verdad-realidad y contaminarse con (o alimentarse de) la perturbadora ficción, el incómodo humor, los sueños, las pesadillas y los fantasmas, los anacronismos, para babelizar las hablas miméticas del realismo, escapar a las certezas y exhibir los mecanismos lingüísticos fabricadores de la ilusión referencial, así como también para mostrar una lengua dañada por el impacto de la violencia y una gramática dislocada por el quiebre de sentido que toda experiencia traumática acarrea. La literatura argentina de hijos/ as de desaparecidos y víctimas -que he explorado en mi libro Infancias. La narrativa argentina de HIJOS (2019) - es un notable ejemplo de este encuentro entre el testimonio y la ficción. Ellos parten de la experiencia propia del terrorismo de Estado, esto es, de un núcleo testimonial que les pertenece por derecho, desde el cual van a jugar para despistarlo, desarticularlo, atravesarlo por la ironía y la burla, quebrarlo con el fantástico y los fantasmas, hacerlo tambalear con la ficción, sin por ello perder su carácter vivencial (“yo estuve allí”). El título del libro de Mariana Eva Pérez, Diario de una princesa montonera -110\% Verdad-, es una síntesis del uso irónico y desenfadado del testimonio que, sin embargo, vertebra su texto. La nouvelle "2073" (2014) de 
Félix Bruzzone y Soy un bravo piloto de la nueva China (2011) de Ernesto Semán constituyen otros ejemplos donde se advierte una reapropiación singular y extrema del testimonio, ya que este se desvía y contamina con la (irreconciliable) ciencia ficción -tal como analizo en "El testimonio y sus fugas hacia la ciencia ficción en la narrativa de HIJOS/AS" (Basile, 2020a).

Este encuentro del testimonio con la literatura y otras formas del arte ha dado lugar a nuevos géneros híbridos como la autoficción (Alberca, 2007; Arfuch, 2013) y la docuficción (Von Tschilschke y Schmelzer, 2010). Ambos géneros comparten la doble y simultánea apuesta a la ficción y a lo "real". El pacto de lectura oximorónica de las autoficciones se edifica a partir de dos lógicas veritativas incompatibles, ya que se parte de la matriz del género autobiográfico sustentada en el estatuto de verdad-falsedad (fundada en la identidad del autor que firma el texto y del protagonista que narra) y se le cruza la ficción de la cual nunca podemos afirmar la verdad-falsedad de lo dicho (en términos lógicos). La ficcionalización del relato autobiográfico o testimonial permite llenar las lagunas de la memoria, cuestionar las certezas de aquello que se expone como una representación fidedigna de lo "real", explorar aquellas zonas fantasmáticas a las que no siempre llega el testimonio, en cambio la dimensión autobiográfica afirma la factualidad de la experiencia sufrida por el narrador.

Por su parte, la docuficción según las perspectivas de Von Tschilschke y Schmelzer (2010) amalgama, con diferente intensidad según el caso, la ficción con el documental. Nuevamente estamos frente a géneros que combinan la posibilidad de falsabilidad de todo documento y su imposibilidad en la ficción, que cruzan un significado vinculado a un referente externo con otro que carece de él en su carácter ficcional. De este modo la docuficción permite anclar la ficción en lo "real" y legitimar su existencia y "verdad". Desde mediados de la década de 1990 se observa el auge de estas formas híbridas en las culturas europeas, norteamericanas y latinoamericanas en diferentes formatos y medios como el docudrama, el docusoap, los documentales ficticios, los largometrajes parcialmente ficticios, la novela a noticia, la docunovela, etc. Este cruce permite proseguir con la tradición posmoderna del juego metaficcional y al mismo tiempo ocuparse de temas relevantes para la sociedad y la política que acaecen por fuera del texto posmoderno, afirman Von Tschilschke y Schmelzer (2010, p. 20).

Otro género que también oscila en un estatuto ambiguo entre lo testimonial y la ficción, pero que no es posible adscribirlo a la autoficción ya que no hay coincidencia entre el autor y el protagonista o porque se reelaboran testimonios de terceras personas, es la novela testimonial. Recuerdo de la Muerte (1984) de Miguel Bonasso, Los compañeros (1987) de Rolo Diez y El fin de la Historia (2007) de Liliana Heker serían algunos ejemplos.

El campo de la literatura y las artes se ha visto sacudido por notables cambios en las últimas décadas que darían cuenta de la complicidad entre testimonio y arte, tales como explican las perspectivas en torno a la postautonomía y a la intermedialidad. Ya nadie intenta buscar el absoluto literario ni conservar la pureza testimonial.

La creciente importancia de los medios tecnológicos o digitales, y su aporte a las prácticas artísticas ha puesto en foco el análisis de la intermedialidad como una nueva vía para comprender estos espacios de intercambio. Provoca la difuminación de las tradicionales fronteras formales y de géneros al incorporar los medios digitales a las prácticas culturales, crea espacios intermediales construidos a partir de la amalgama entre diversos modelos de representación y creación de significados, y da lugar a la proliferación de textos, intertextos, hipertextos o hiperficciones. La intermedialidad deconstruye la pureza de los géneros y las jerarquías entre las artes al combinar medios tradicionales como la ópera, el cine, el teatro, los performances, las instalaciones de arte, los cómics y otros con los multimedia o medios asociados a las nuevas tecnologías para construir un nuevo producto (Cubillo Paniagua, 2013).

En "Literaturas postautónomas" (2007) Josefina Ludmer se propone explorar la lógica postautónoma que administraría el estatuto de la literatura en el presente, signada por el debilitamiento de la autonomía del arte que da paso al régimen de ficción/realidad, o de lo real/virtual o a un intercambio entre la literatura y 
ciertos medios como la televisión, los blogs, Internet, email, etc., tendientes a fabricar escrituras actuales de la realidad cotidiana. Adoptan la forma del testimonio, la autobiografía, el reportaje periodístico, la crónica, el diario íntimo, y hasta la etnografía.

¿Cómo podemos reflexionar sobre el lugar y las transformaciones del testimonio sobre la violencia de la historia reciente desde estos procesos de hibridación (autoficción y docuficción) en los nuevos contextos del presente (intermedialidad y postautonomía)? Evidentemente se advierte un cruce entre dos tendencias. Por un lado, el clima cultural del fin de siglo con la pérdida de las certezas, el fin de las utopías, la crítica a las macronarrativas, el giro lingüístico, la deconstrucción, el debate sobre la posmodernidad, y la expansión y diversificación de las identidades con sus relatos ad hoc que han provocado la puesta en foco de la ficcionalidad y mediación de toda representación así como han deconstruido el carácter absoluto y totalizante de la "verdad". Por el otro, el regreso de lo "real" propulsado por la ineludible experiencia de la dictadura que desembarca con todo el peso de lo factual, que precisa conocerse en su verdad, que exige las listas de desaparecidos y niños robados, que constata sitios de campos clandestinos, que busca y desentierra huesos, que persigue la identidad en la sangre, que expone el cuerpo torturado, desaparecido, apropiado, todo un universo "real" que justamente fue negado y ocultado en su factualidad por los perpetradores.

Atestiguar el acontecimiento, afirmar la vivencialidad testimonial y autobiográfica del mismo ("yo estuve allí”) y dotarla de legitimidad a través del documento, pero atendiendo al mismo tiempo a las lagunas de la memoria y a las posibilidades de la ficción para penetrar en aquello que ni el testimonio ni el documento pueden explorar, permite explicar la necesidad de estos géneros híbridos. No estaríamos asistiendo a la pérdida del poder crítico, emancipador y hasta subversivo, ni al debilitamiento del sentido. Por otro lado, en la literatura de hijas/os esta voluntad de apresar lo real apunta no sólo a su sentido literal, además supone aquello que escapa a la representación en términos de Lacan. Tanto la experiencia como el testimonio, aun cuando trabajan con lo real, se constituyen como espacios agrietados y controvertidos: la violencia radical, intolerable para el sujeto, provoca la escisión de la experiencia que queda latente, obtura la cognición y el arribo a las certezas (Basile 2019a: 36).

La variedad de cruces entre testimonios y documentos con diversas formas de arte traza una de las líneas más productivas y creativas del presente, cuya riqueza sería imposible contabilizar, pero podemos referirnos a algunos ejemplos. Así, el trabajo reelaborativo de fotografías de detenidos-desaparecidos, víctimas y familiares por parte de Lucila Quieto, Gustavo Germano, Marcelo Brodsky, Julio Pantoja, Inés Ulanovsky, entre otros. También la producción cinematográfica ha utilizado el testimonio y el documento como sus plataformas, tal como puede apreciarse en los films de hijos/as argentinos quienes suelen tematizar la búsqueda de datos, la revisión de archivos, la visita a los centros de detención, la recolección de testimonios de los compañeros de militancia de sus padres (en ocasiones cuestionarlos) en películas como Papá Iván (María Inés Roqué, 2000), Los Rubios (Albertina Carri, 2003), Encontrando a Victor (Natalia Bruschtein, 2004) o M (Nicolás Prividera, 2007).

El teatro exhibe toda una trayectoria documental, visible especialmente en el denominado teatro por la identidad (https://teatroxlaidentidad.net/), uno de los brazos artísticos de Abuelas de Plaza de Mayo que colabora en la ardua tarea de encontrar a los nietos apropiados. Pero en esta ocasión quiero detenerme en las propuestas de Lola Arias cuya Mi vida después (2009) parece sintetizar varias de las cuestiones aquí planteadas. En primer lugar no estamos frente a una propuesta exclusivamente ficcional sino a un biodrama que supone un trabajo (remake) a partir de la vida del actor. En este caso se escogieron seis actores nacidos en los $70 \mathrm{y}$ principios de los 80 que reconstruyen la juventud de sus padres (un guerrillero del Ejército Revolucionario del Pueblo, un oficial de inteligencia, un cura, padres exiliados, etc.), ilustrando desde diferentes perfiles el contexto de violencia que en su momento vivieron (Arias, 2016).

Estas remake de escenas del pasado se disparan a partir de dispositivos testimoniales como fotos, cartas, ropa usada, juguetes, periódicos, grabaciones, el expediente de un juicio, relatos y recuerdos que les permiten también despertar la imaginación, explorar esos destinos e imaginar el futuro. Lejos de una voluntad que 
reifique el pasado, se propugna reinventar el pasado en el presente. Por ello, Mi vida después transita en los bordes entre lo real y la ficción, sostiene Arias, quien advierte que la categoría de "teatro documental" con la que nombran su obra supone una barrera entre un teatro de ficción y un teatro documental que ella procura diluir (Brownell, 2009). Por otro lado, se entrelazan las historias de los performers con dispositivos escénicos muy variados, que articulan múltiples recursos musicales, coreográficos y multimediáticos.

Finalmente no quiero dejar de mencionar los aportes de historietas, cómics, novelas gráficas, cómic periodístico sobre la dictadura argentina que incluyen en su centro el testimonio, pero van más allá de él para experimentar con la fragmentación, la yuxtaposición, el grotesco, lo monstruoso, el absurdo, la ironía, el humor o lo naif. En cierta medida se vinculan con una notable tradición argentina en este género bajo la obra central de Héctor Oesterheld, desaparecido en 1977, y de varias revistas como Satiricón y Humor que sufrieron en su momento la censura. Junto a toda una producción que aborda modos de narrar el terrorismo de Estado desde el cómic y la historieta que ya cuenta con un abultado corpus (Hildebrandt, 2006), encontramos la propuesta de Historietas por la identidad encarada por Abuelas de Plaza de Mayo

\section{LEGADOS EN FUTURO}

En su conferencia del Congreso LASA de Montreal en 2007, John Beverley invitó a repensar el legado de la lucha armada en América Latina, un reexamen que trascienda la actitud de "arrepentimiento picaresco" a que el tema fue condenado durante el auge del pensamiento neoliberal y reclama que "hace falta hoy más que nunca recuperar la herencia de la lucha armada, no sin un sentido de distancia, a la vez histórica y crítica no se trata de idealizar o repetir fórmulas anticuadas- pero sí con espíritu de admiración, amor y respeto", nos cuenta Juan Duchesne Winter (2010, p. 9). A su vez y en esta línea, el mismo Duchesne Winter en La guerrilla narrada: acción, acontecimiento, sujeto (2010) procura repensar este tema y propone revisar el foco guerrillero que condujo a fracasos y derrotas, mirar críticamente la violencia armada con su forma de ejercer el poder y evaluar los alcances y límites de los movimientos insurreccionales, más allá de la derrota o la victoria. Reconoce el derecho a la insurrección de los pueblos en situaciones de tiranía, pero propone desenfocar el foco en los siguientes términos: "Este desenfoque compete a la muy importante distinción entre la derrota de una concepción dada de la insurrección, y el fracaso de la insurrección misma, es decir, de la lucha armada como opción política y como derecho irrenunciable de los pueblos ante situaciones específicas de despotismo, incluido el despotismo de regímenes resultantes de una lucha armada popular y fundados en el prestigio de este tipo de legado" (2010, p. 75). Por su parte y en su recorrido analítico por varios testimonios de Ernesto "Che" Guevara, Jaume Peris Blanes se pregunta por el valor "constituyente" de estos relatos para las luchas futuras, no solo aquellas insurrecciones que el mismo Guevara proyectaba, sino asimismo las de carácter potencial "lo que todavía no ha llegado, pero pugna por emerger, a las luchas e insurrecciones futuras que necesitarán relatos constituyentes sobre los que sostenerse para echar a andar", lo que implicaría "reconsiderar la función posible de las producciones testimoniales y su rol en los proceso de transformación social” (2015, p. 186). También Ana María Amar Sánchez en Instrucciones para la derrota. Narrativas éticas y politicas de perdedores (2010) se pregunta por las posibles maneras de sobrevivir luego de la derrota de los movimientos revolucionarios por parte de los perdedores y los derrotados en diversas coyunturas políticas. Una manera diferente que no lleve a la adaptación, a la resignación sin esperanza, a la traición, a los pactos o al olvido. De allí que destaque la figura del "perdedor ético" capaz de indagar modos de renacer y caminos para resistir.

Estas perspectivas de John Beverley, Juan Duchesne Winter, Jaume Peris Blanes y Ana María Amar Sánchez que hemos tomado a modo de ejemplo calan en el hueso de la cuestión que hemos procurado comenzar a interrogar en este artículo y que sintetizo en la siguiente pregunta: ¿podemos pensar el legado de los testimonios de matriz revolucionaria en el presente sin considerar y por fuera de la matriz de los derechos humanos?, ¿cuál sería el impacto que los derechos humanos ejercen en el legado revolucionario?, ¿qué resulta obsoleto y qué es factible de recuperar de la lucha armada de los 60 y de sus discursos? Si la narrativa 
humanitaria parece haber sustituido en gran medida aquel horizonte de las luchas revolucionarias, entonces ¿cuál sería su impacto en el interior de esta nueva coyuntura tanto en las prácticas políticas, militantes y judiciales como en las escrituras y discursos?

Mientras en su primer modelo el testimonio auguraba la revolución, este segundo patrón proyecta la democracia y los derechos humanos al tiempo que clausura tanto las posibilidades de las dictaduras como las de la lucha de la izquierda armada, lo que se hace evidente en el contexto del fin de la Guerra Fría y en el debilitamiento del horizonte revolucionario para América Latina. La peculiar politicidad de la matriz de los derechos humanos, inaugurada en el Nunca Más y enarbolados en los Juicios a las Juntas, va a reconfigurar las subjetividades e identidades, va a moldear y crear instituciones, se va a colar en la justicia, en la educación, en el lenguaje, en los imaginarios sociales y en el arte, va a impregnar y redireccionar las militancias hacia las luchas por la memoria, la verdad y la justicia. También será apropiada con otros fines por los ex represores, por aquellos hijos que los defienden, por las derechas, por el neoliberalismo. Será, entonces, en ese territorio y en ese lenguaje donde parecen dirimirse varias de las actuales luchas. Podemos considerar que estamos frente a un corte epistemológico que redefine no solo la factura del testimonio, sino los modos de hacer política, militancia, justicia, identidades y cultura.

\section{RefERENCiAS}

Achugar, H. (comp.) (2002). En otras palabras, otras historias. Montevideo: Universidad de la República.

Agamben, G. (1999). Homo sacer I. El poder soberano y la nuda vida. Valencia: Pretextos.

Amar Sánchez, A. M. (1992). El relato de los hechos. Rodolfo Walsh: testimonio y escritura. Beatriz Viterbo Editora: Rosario.

Amar Sánchez, A. M. (2010). Instrucciones para la derrota. Narrativas éticas y políticas de perdedores. Barcelona: Anthropos Editorial.

Arfuch, L. (2013). Memoria y autobiografía. Exploraciones en los límites. Buenos Aires: Fondo de Cultura Económica. Arias, L. (2016). Mi vida después y otros textos. Buenos Aires: Reservoir Books.

Barnet, M. (1981). La fuente viva. La Habana: Editorial Letras Cubanas.

Barnet, M. (1986). Biografía de un cimarrón. La Habana: Ciencias Sociales.

Bartalini, C. et al. (eds.) (2018). Escritos desobedientes. Historias de hijas, hijos y familiares de genocidas por la memoria, la verdad y la justicia. Buenos Aires: Marea.

Basile, T. (1998). Aproximaciones al "testimonio sobre la desaparición de personas" durante la dictadura y la democracia argentinas. Alp: Cuadernos Angers-La Plata, 2(2), 45-64.

Basile, T. (2018). El desarme de Calibán. Debates culturales y diseños literarios en la posdictadura uruguaya. Pittsburgh: University of Pittsburgh.

Basile, T. (2019a). Infancias. La narrativa argentina de HIJOS. Villa María: EDUVIM.

Basile, T. (2019b). Reseña del libro Escritos desobedientes. Historias de hijas, hijos y familiares de genocidas por la memoria, la verdad y la justicia de Analía Kalinec (comp.). Aletheia, 9(18), 1-3. Recuperado de: https://doi.or $\mathrm{g} / 10.24215 / 18533701 \mathrm{e} 017$

Basile, T. (2020a). El testimonio y sus fugas hacia la ciencia ficción en la narrativa de HIJOS/AS. En T. Basile y M. Chiani (Eds.), Voces de la violencia. Avatares del testimonio en el Cono Sur (pp. 339-360). La Plata: EDULP.

Basile, T. (2020b). Padres perpetradores. Perspectivas desde los hijos e hijas de represores en Argentina. Kamchatka.Revista de análisis cultural, 15, 127-157. Recuperado de: https://doi.org/10.7203/KAM.15.15714

Basile, T. (2020c). Los objetos en los escenarios de la memoria: aproximaciones teóricas y análisis de ejemplos referidos a los hijos de desaparecidos en Argentina. Kamchatka. Revista de análisis cultural, 16, 319-348 (En prensa).

Basile, T. (2020d). De la posmemoria a la doble memoria. Tópicos Del Seminario, 2(44), 84-111. Recuperado de:http ://www.topicosdelseminario.buap.mx/index.php/topsem/article/view/702 
Basile, T. (2020e). Apropiación y restitución en la narrativa de los hijos de desaparecidos de la dictadura argentina: los desaparecidos vivos. Kamchatka. Revista de análisis cultural, 15, 335-367. Recuperado de: https://doi.org/ 10.7203/KAM.15.16651

Basile, T. y Chiani, M. (2020). Introducción. Avatares del testimonio en el Cono Sur. En T. Basile y M. Chiani (Eds.), Voces de la violencia. Avatares del testimonio en el Cono Sur (pp. 11-34). La Plata: EDULP.

Basile, T. y González, C. (2020). Las posmemorias en acto. En T. Basile y C. González (Eds.), Las posmemorias: Perspectivas latinoamericanas y europeas (pp. 9-30). La Plata: Fahce-Universidad Nacional de La Plata; Bordeaux: Presses Universitaires de Bordeaux.

Beverley, J. (1987). Anatomía del testimonio. Revista de Critica Literaria Latinoamericana, 25, 7-16.

Beverley, J. (1989). The Margin at the Center: On Testimonio. MFS Modern Fiction Studies, 35(1), 11-28.

Brownell, P. (2009). El teatro antes del futuro: sobre Mi vida después de Lola Arias. Telondefondo. Revista de Teoría y Critica Teatral, 10, 1-13.

Burgos Debray, E. (1983). Me llamo Rigoberta Menchú. Cuba: Casa de las Américas.

Bürger, P. (1974). Teoría de la vanguardia. Barcelona: Ediciones Península.

Castro,F. (2007). La historia me absolverá. La Habana: Editorial de Ciencias Sociales.

CONADEP (1984). Nunca más, informe final de la Comisión Nacional sobre la Desaparición de Personas. Buenos Aires: EUDEBA.

Cornejo Polar. A. (1978). El indigenismo y las literaturas heterogéneas: su doble estatuto sociocultural. Revista de Critica Literaria latinoamericana, 7/8, 101-122.

Crenzel, E. (2008). La historia politica del Nunca Más: la memoria de las desapariciones en la Argentina. Buenos Aires: Siglo XXI.

Cubillo Paniagua, R. (2013). La intermedialidad en el siglo XXI. Diálogos Revista Electrónica de Historia, 14(2), 169-179. Recuperado de: http://www.scielo.sa.cr/scielo.php?script=sci_arttext\&pid=S1409-469X201300020 $0006 \& \operatorname{lng}=\mathrm{en} \& \mathrm{t} \operatorname{lng}=\mathrm{es}$

Duchesne Winter, J. (2010). La guerrilla narrada: acción, acontecimiento, sujeto. San Juan de Puerto Rico: Ediciones Callejón.

Fanon, F. (1963). Los condenados de la tierra. México: Fondo de Cultura Económica.

Feld, C. (2002). Del estrado a la pantalla: las imágenes del juicio a los ex comandantes en Argentina. Madrid: Siglo XXI.

Feld, C. (2010). La representación de los desaparecidos en la prensa de la transición: el show del horror. En E. Crenzel (coord.), Los desaparecidos en la Argentina: memorias, representaciones e ideas: 1983-2008 (pp. 25-41). Buenos Aires: Biblos.

Feld, C. (2015). Imagen y testimonio frente a la desaparición forzada de personas en la Argentina de la transición. Kamchatka, 6, 687-715.

Feierstein, D. (2007). El genocidio como práctica social. Entre el nazismo y la experiencia argentina. Buenos Aires: Fondo de Cultura Económica.

Fernández Retamar, R. (1984). Calibán. Apuntes sobre la cultura de nuestra América. Buenos Aires: Editorial La Pléyade.

Franco, J. (1992). "Si me permiten hablar": La lucha por el poder interpretativo. Revista de Crítica Literaria Latinoamericana, 36, 111-118.

Friedlander, S. (comp.) (2007). En torno a los límites de la representación. El nazismo y la solución final. Quilmes: UnQui Editorial.

García, V. (2014). Testimonio literario latinoamericano: prefiguraciones históricas del género en el discurso revolucionario de los años sesenta. Acta Poética, 35(1), 63-92.

Gilman, C. (2003). Entre la pluma y el fusil. Debates y dilemas del escritor revolucionario en América Latina. Buenos Aires: Fondo de Cultura Económica.

Guevara, E. (1985). Pasajes de la guerra revolucionaria. La Habana: Editorial de Ciencias Sociales. 
Guevara, E. (1965). El socialismo y el hombre en Cuba. Marcha, 1246, 14-15.

Guglielmucci, A. (2017). El concepto de víctima en el campo de los derechos humanos: una reflexión crítica a partir de su aplicación en Argentina y Colombia, Revista de Estudios Sociales, 59, 83-97.

Habermas, J. (2000). Sobre el uso público de la Historia. En J Habermas, La constelación posnacional. Ensayospolíticos. (pp. 43-55). Barcelona: Paidós.

Hildebrandt, J. (2006). Censurado: la Dictadura y la historieta argentina. Sudestada, 47. Recuperado de: https://ww w.revistasudestada.com.ar/articulo/280/censurado-la-dictadura-y-la-historieta-argentina/

Jara, R. (1986). Testimonio y Literatura. En R. Jara y H. Vidal (eds.), Testimonio y Literatura (pp.1-6). Minneapolis: Institute for the Study of Ideologies and Literature.

Jozami, E. (2013). Rodolfo Walsh, la palabra y la acción. Buenos aires: Edhasa.

Kaufman, S. (2006). Lo legado y lo propio. Lazos familiares y transmisión de memorias. En E. Jelin y S. Kaufman (eds.). Subjetividad y figuras de la memoria (pp. 47-71). Buenos Aires: Siglo XXI.

Kaufman, S. (2000) Perspectivas subjetivas sobre el testimonio: Experiencias límite, lenguaje y representación. En T. Basile y M. Chiani (eds.), Voces de la violencia. Avatares del testimonio en el Cono Sur (pp. 57-70). La Plata: EDULP.

Longoni, A. (2007). Traiciones. La figura del traidor en los relatos acerca de los sobrevivientes de la represión. Buenos Aires: Norma.

Ludmer, J. (2007). Literaturas postautónomas. Ciberletras.Revista de crítica literaria y de cultura, 17. Recuperado de: http://www.lehman.cuny.edu/ciberletras/v17/ludmer.htm

Moraña, M. (1997). Documentalismo y ficción: testimonio y narrativa testimonial hispanoamericana en el siglo XX. En M. Moraña (ed.), Politicas de la escritura en América Latina: de la Colonia a la Modernidad (pp.113-150). Caracas: Ex-cultura.

Nofal, R. (2002). La escritura testimonial en América Latina. San Miguel de Tucumán: Universidad Nacional de Tucumán.

Prada Oropeza, R. (1986). De lo testimonial al testimonio. Notas para un deslinde del discurso-testimonio. En R. Jara y H. Vidal (eds.), Testimonio y Literatura (pp.7-21). Minneapolis: Institute for the Study of Ideologies and Literature.

Perassi, E. (2015). Desde el cuerpo de las madres: nuevas figuraciones del testimonio después del testimonio. En F. Reati y M. Cannavacciuolo (comps.), De la cercanía emocional a la distancia histórica. (Re)presentaciones del terrorismo de Estado, 40 años después (pp. 227-242). Buenos Aires: Prometeo Libros.

Perassi, E. (2017). Construyendo memorias colectivas: la literatura italiana y la dictadura militar argentina. En C. Cattarulla (comp.), Argentina 1976-1983. Imaginarios italianos (pp.13-31). Villa María: Eduvim.

Peris Blanes, J. (2015). Relatos para una revolución potencial. Las crónicas testimoniales de Che Guevara. Kamchatka, 6, 149-190.

Peris Blanes, J. y Palazón Sáez, G. (2015). Presentación del Dossier "Avatares del testimonio en América Latina: tensiones, contradicciones, relecturas...”, Kamchatka, 6, pp. 1-8.

Piglia, R. (1970). Entrevista de Ricardo Piglia a Rodolfo Walsh: "No concibo el arte si no está relacionado con la política". Cuba Debate, 19 de agosto de 2017. Recuperado de http://www.cubadebate.cu/especiales/2017/08/1 9/entrevista-de-ricardo-piglia-a-rodolfo-walsh-no-concibo-el-arte-si-no-esta-relacionado-con-la-politica/

Poniatowska, E. (2015). La noche de Tlatelolco. Buenos aires: Marea.

Roniger, L. (2018). Historia minima de los derechos humanos en América Latina. México: Colegio de México.

Salvi, V. (2012). De vencedores a victimas: memorias militares sobre el pasado reciente en la Argentina. Buenos Aires: Biblos.

Sarlo, B. (2005). Tiempo pasado. Cultura de la memoria y giro subjetivo. Una discusión. Buenos Aires: Siglo XXI.

Sklodowska, E. (1982). La forma testimonial y la novelística de Miguel Barnet. Revista/Review Interamericana, XII(3), 375-384. 
Sklodowska, E. (1988). Miguel Barnet: Hacia la poética de la novela testimonial. Revista de Crítica Literaria latinoamericana, 27, 139-149.

Sklodowska, E. (1992). Testimonio hispanoamericano: historia, teoría, poética. New York: Peter Lang.

Sklodowska, E. (1993). Testimonio mediatizado: ¿ventriloquia o heteroglosia? (Barnet/Montejo; Burgos/Menchú), Revista de Critica Literaria Latinoamericana, 38, 81-90.

Sklodowska, E. (2002). Miguel Barnet y la novela-testimonio. Revista Iberoamericana, LXVIII (200), 799-806.

Spivak, G. (1998). ¿Puede hablar el sujeto subalterno? Orbis Tertius, 3(6), 175-235. Recuperado de: https://www.or bistertius.unlp.edu.ar/article/view/OTv03n06t01/3976

Traverso, E. (2007). Historia y memoria. Notas sobre un debate. En M. Franco y F. Levin (comps.), Historia reciente. Perspectivas y desafios de un campo en construcción (pp. 67-96). Buenos Aires: Paidós.

Vecchioli, V. (2001). Políticas de la Memoria y Formas de Clasificación Social. ¿Quiénes son las `Víctimas del Terrorismo de Estado' en la Argentina? En B. Groppo y P. Flier (comp.), La imposibilidad del Olvido. Recorridos de la Memoria en Argentina, Chile y Uruguay (pp. 83-102). La Plata: Ediciones Al Margen.

Vezzetti, H. (2009). Sobre la violencia revolucionaria. Memorias y olvidos. Buenos Aires: Siglo XXI.

Viezzer, M. (2005). Si me permiten hablar...Testimonio de Domitila, una mujer de las minas de Bolivia. México: Siglo XXI. Recuperado de http://www.cmpa.es/datos/6816/VIEZZE-Memorias_de_Domitila60.pdf

Von Tschilschke, C. y Schmelzer, D. (2010). Docuficción: un fenómeno limítrofe se aproxima al centro. En C. von Tschilschke, D. Schmelzer (eds.), Docuficción. Enlaces entre ficción y no-ficción en la cultura española actual (pp. 11-32), Madrid: Iberoamericana Vervuert.

Walsh, R. (2020). Operación masacre. Buenos Aires: Ediciones de la Flor.

White, H. (1992), Metahistoria. La imaginación histórica en la Europa del siglo XIX. México: Fondo de Cultura Económica.

Wieviorka, A. (1998). L'ére du témoin. Paris: Plon.

\section{Notas}

1 Una primera versión de este artículo se publicó como "Introducción. Avatares del testimonio en el Cono Sur” en Voces de la violencia. Avatares del testimonio en el Cono Sur, Teresa Basile y Miriam Chiani (eds.). La Plata: EDULP, 2020, pp. 11-34.

2 Sklodowska expone un exhaustivo e interesante "estado de la cuestión" en los primeros dos capítulos de su libro donde repasa los debates del momento en torno a las características del testimonio, a las perspectivas que procuraron definirlo, a las clasificaciones y tipologías, entre otras cuestiones (1992, p. 7-107).

3 La CONADEP (Comisión Nacional sobre la Desaparición de Personas) fue creada por el presidente argentino Raúl Alfonsín el 15 de diciembre de 1983 con el objetivo de investigar las reiteradas y planificadas violaciones a los derechos humanos ocurridas durante la dictadura (1976-1983).

4 Analizo el trazado de una genealogía revolucionaria llevado a cabo en estos dos textos a partir de la experiencia de la Revolución cubana en Basile (2018). 